Test Methods and Protocols for Environmental and Safety Hazards Associated With Home Energy Retrofits

D. Cautley, J. Viner, M. Lord, and M. Pearce NorthernSTAR Building America Partnership 


\section{NOTICE}

This report was prepared as an account of work sponsored by an agency of the United States government. Neither the United States government nor any agency thereof, nor any of their employees, subcontractors, or affiliated partners makes any warranty, express or implied, or assumes any legal liability or responsibility for the accuracy, completeness, or usefulness of any information, apparatus, product, or process disclosed, or represents that its use would not infringe privately owned rights. Reference herein to any specific commercial product, process, or service by trade name, trademark, manufacturer, or otherwise does not necessarily constitute or imply its endorsement, recommendation, or favoring by the United States government or any agency thereof. The views and opinions of authors expressed herein do not necessarily state or reflect those of the United States government or any agency thereof.

Available electronically at www.osti.gov/bridge

Available for a processing fee to U.S. Department of Energy and its contractors, in paper, from:

U.S. Department of Energy

Office of Scientific and Technical Information

$$
\text { P.O. Box } 62
$$

Oak Ridge, TN 37831-0062

phone: 865.576.8401

fax: 865.576.5728

email: mailto:reports@adonis.osti.gov

Available for sale to the public, in paper, from:

U.S. Department of Commerce

National Technical Information Service

5285 Port Royal Road

Springfield, VA 22161

phone: 800.553 .6847

fax: 703.605.6900

email: orders@ntis.fedworld.gov

online ordering: www.ntis.gov/ordering.htm

\footnotetext{
Printed on paper containing at least $50 \%$ wastepaper, including $20 \%$ postconsumer waste
} 


\title{
Test Methods and Protocols for Environmental and Safety Hazards Associated With Home Energy Retrofits
}

\author{
Prepared for: \\ The National Renewable Energy Laboratory \\ On behalf of the U.S. Department of Energy's Building America Program \\ Office of Energy Efficiency and Renewable Energy \\ 15013 Denver West Parkway \\ Golden, CO 80401 \\ NREL Contract No. DE-AC36-08GO28308
}

Prepared by:

D. Cautley, J. Viner, M. Lord, and M. Pearce

NorthernSTAR Building America Partnership

2400 Folwell Avenue

St. Paul, MN 55108

NREL Technical Monitor: Stacey Rothgeb

Prepared under Subcontract No. KNDJ-0-40338-00

December 2012 
[This page left blank] 


\section{Contents}

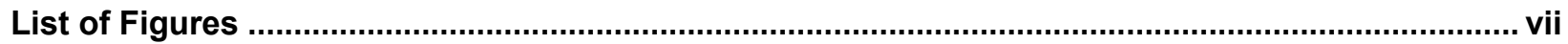

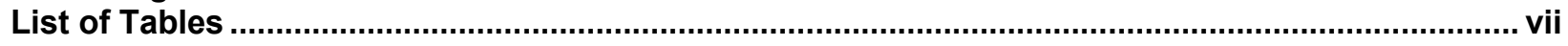

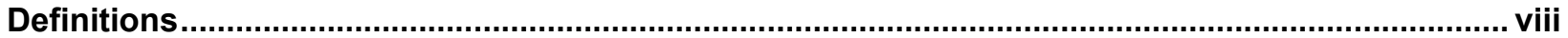

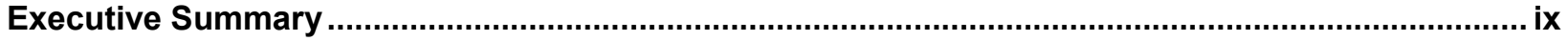

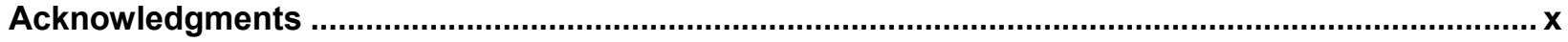

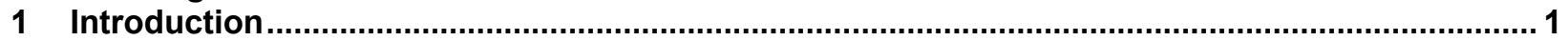

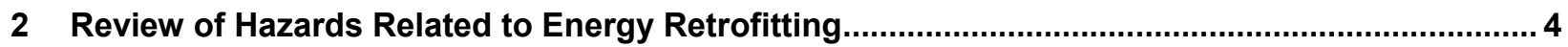

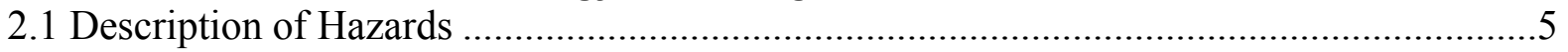

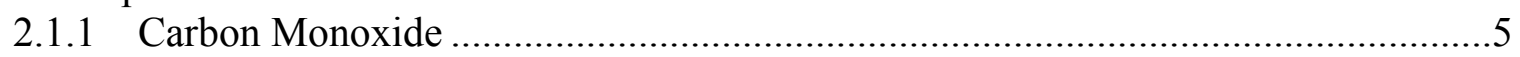

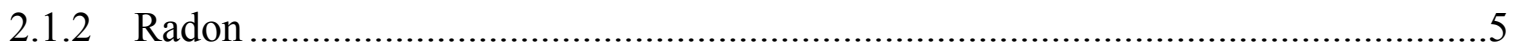

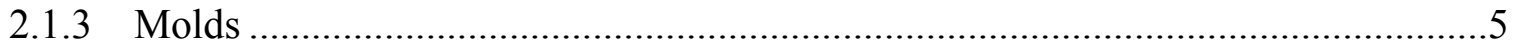

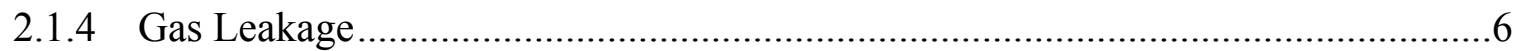

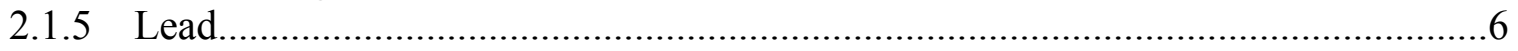

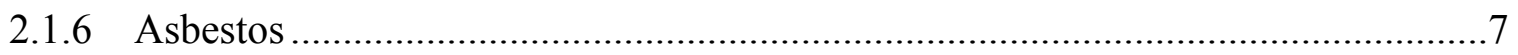

2.1.7 Formaldehyde ........................................................................................

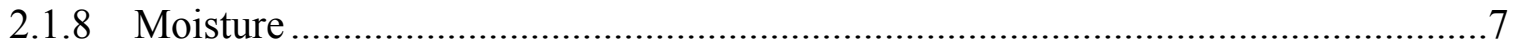

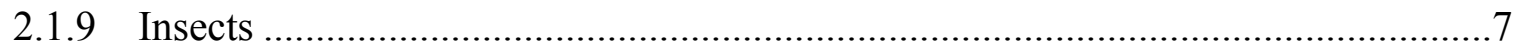

2.1.10 Particulates .......................................................................................

3 Rates of Illness, Injury, and Death Associated With Hazards in the Home ................................. 9

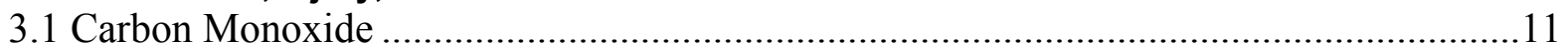

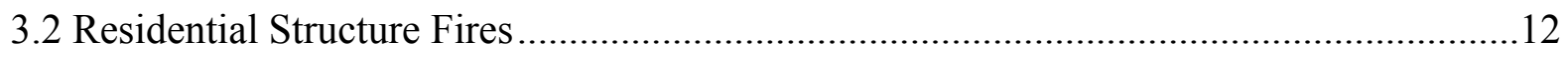

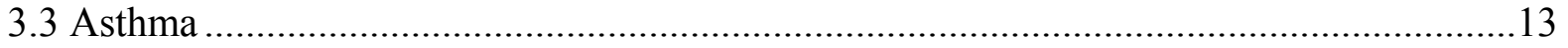

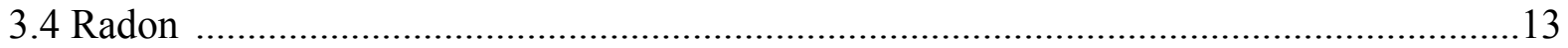

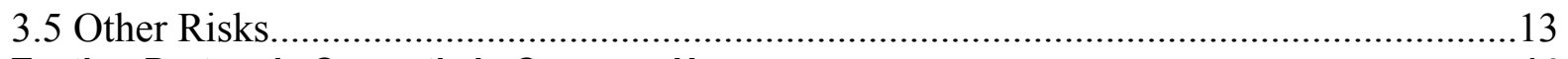

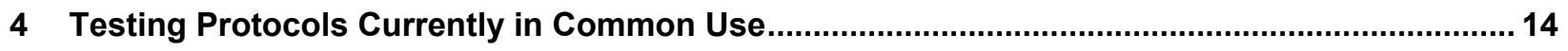

4.1 Test in, Test out Concept ...................................................................................... 17

4.2 Indoor Environmental Quality and Durability Testing Outside Organized Energy

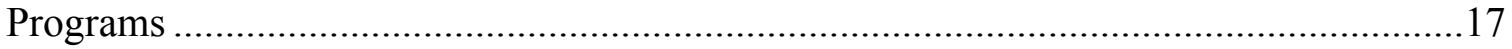

5 Indoor Environmental Quality and Durability Test Methods .......................................... 18

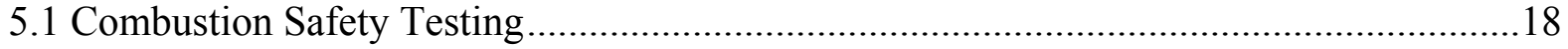

5.1.1 Combustion Appliance Zone Worst Case Depressurization...............................18

5.1 .2 Vent Spillage Tests ............................................................................... 19

5.1.3 Carbon Monoxide Production ........................................................................20

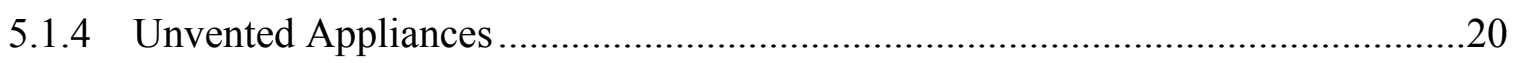

5.1.5 Gas Leakage and Other Identification of Combustibles ..................................21

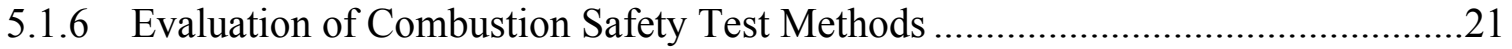

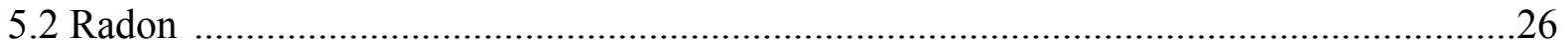

5.2.1 Evaluation of Radon Test Methods................................................................26

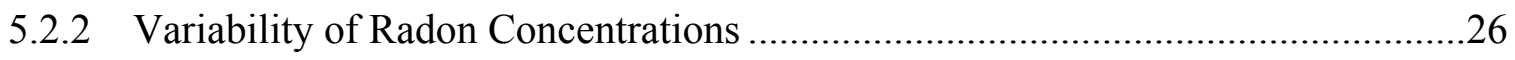

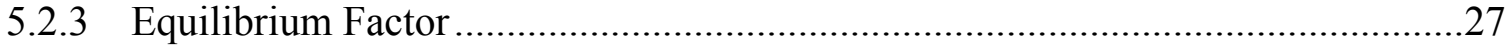

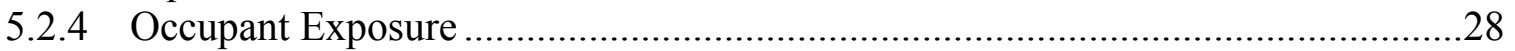

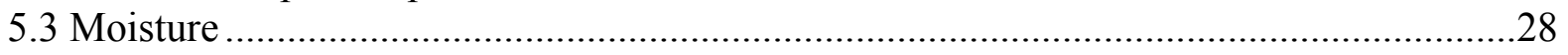

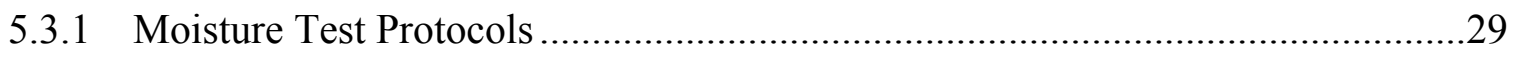

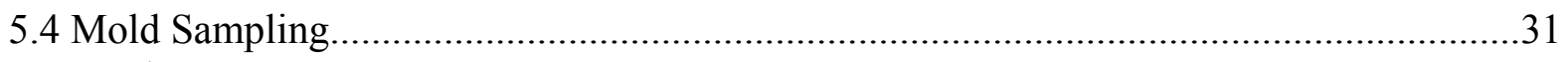

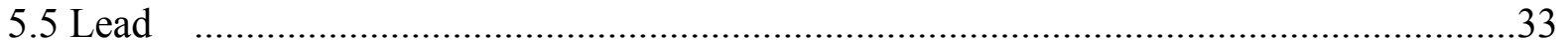

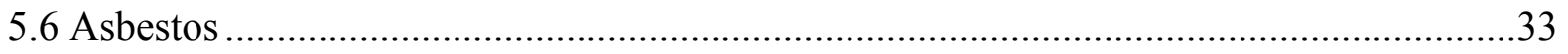




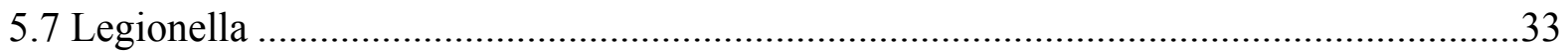

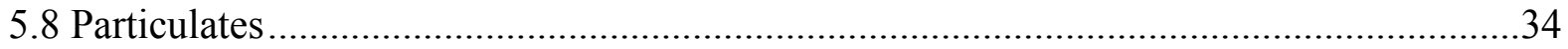

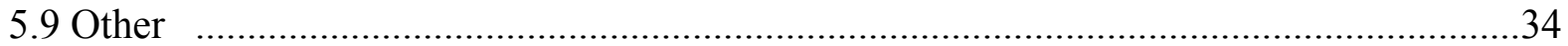

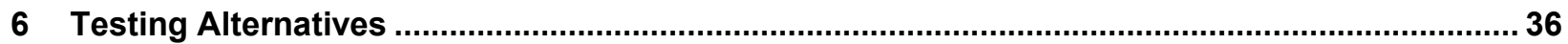

6.1 Combustion Safety Evaluation .....................................................................................

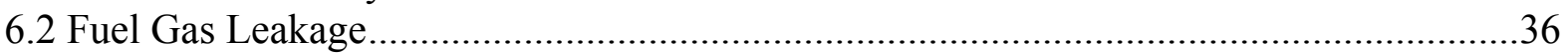

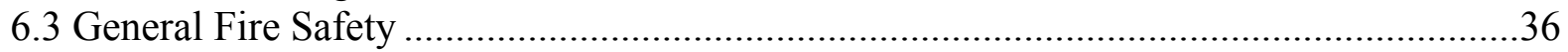

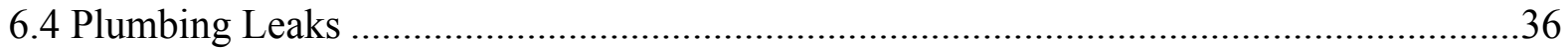

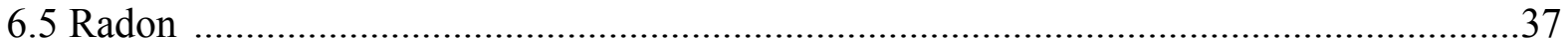

6.5.1 Radon on Glass - Retrospective Estimates..........................................................37

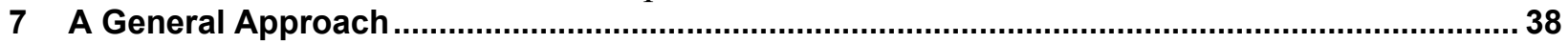

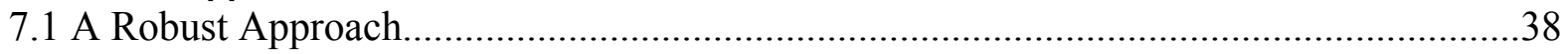

7.2 Outline of a Comprehensive Approach to Indoor Environmental Quality and Durability in

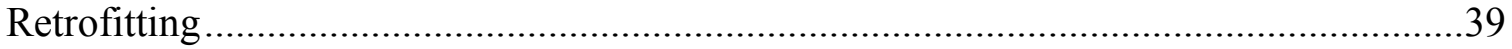

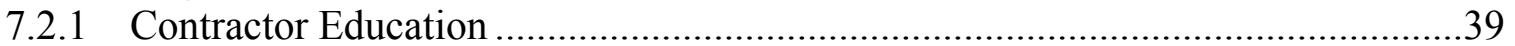

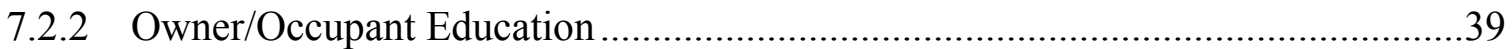

7.2.3 Indoor Environmental Quality and Durability Standards .......................................40

7.2.4 Design and Product Selection ............................................................................40

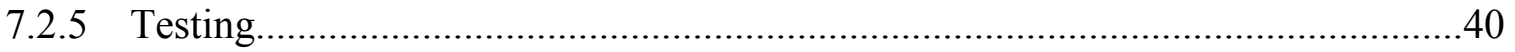

7.2.6 Identification and Notification During Course of Work ..........................................41

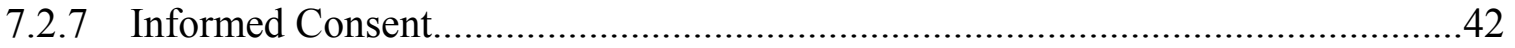

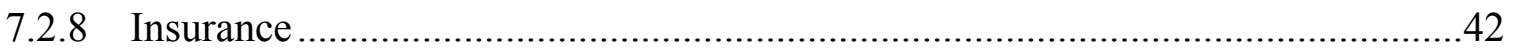

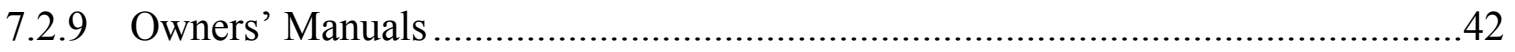

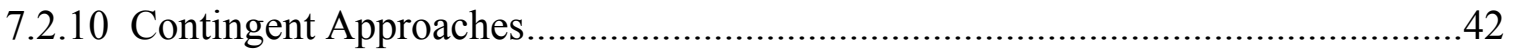

7.2.11 Corporate Engagement..................................................................................

7.3 Recommendations for Addressing Indoor Environmental Quality and Durability in

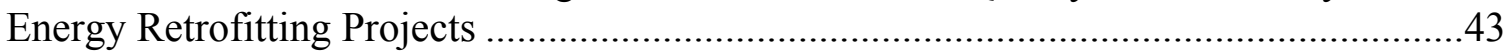

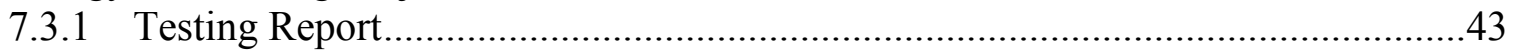

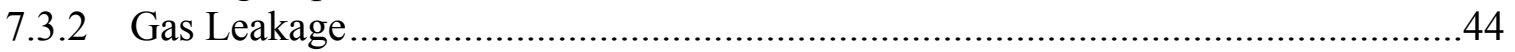

7.3.3 Combustion Safety, Vented Appliances ………………………….....................4

7.3.4 Carbon Monoxide Production, Unvented Appliances ……………………….........4

7.3.5 Vent and Chimney Inspection of Other Appliances ...............................................45

7.3.6 Carbon Monoxide Alarms......................................................................................45

7.3.7 Walk-Through Inspection for Moisture Accumulation and Mold Growth.............45

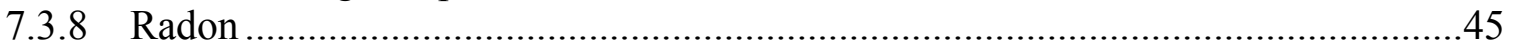

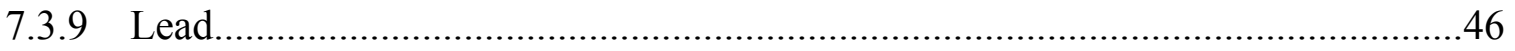

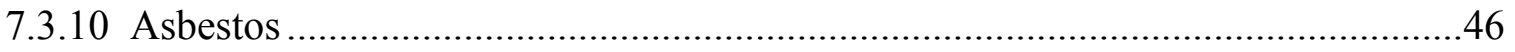

7.3.11 Hot Water Temperature ………………………….........................................46

7.3.12 Notification Provision in All Contracts and Subcontracts ......................................46

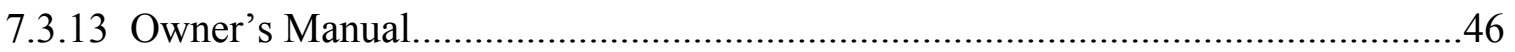

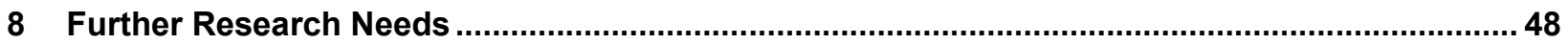

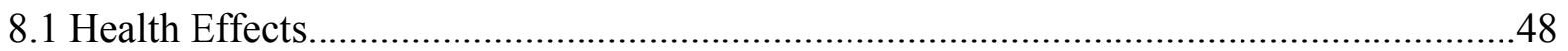

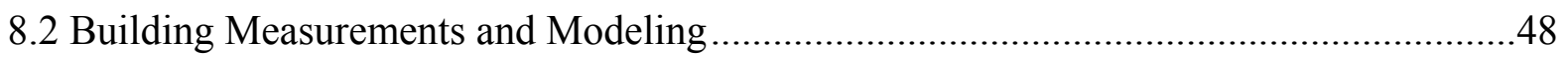

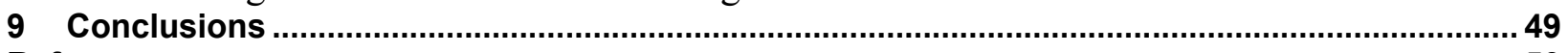

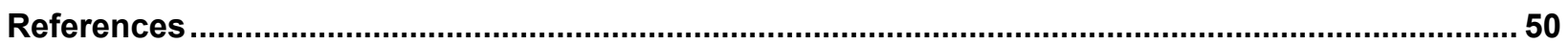

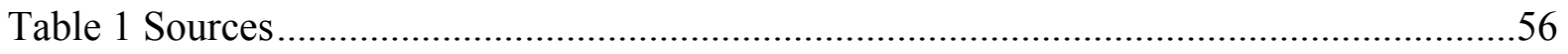

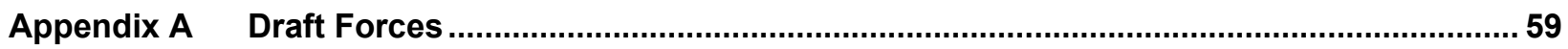

Appendix B Radon Measurement Method Definitions ...............................................................61 


\section{List of Figures}

Figure 1. Estimated annual number of U.S. deaths from various causes 10

Figure 2. Theoretical chimney draft for varying vent temperatur rise (low range) at $T_{\text {out }}=60^{\circ} \mathrm{F}$

Unless otherwise indicated, all figures were created by NorthernSTAR.

\section{List of Tables}

Table 1. Illnesses, Injuries, and Deaths Attributable to Home-Related Hazards in the United States

Table 2. Estimated Annual Carbon Monoxide Poisoning Deaths Due to Fuel-Burning Consumer Products, 2005-2007

Table 3. Unweighted Number of Nonfatal, Unintentional, Nonfire-Related Carbon Monoxide

Exposures by Source, 2001-2003

Table 4. Estimated Number of Residential Fires in 2008

Table 5. Written Standards to Assess Risk Before Work Begins .

Table 6. IEQ and Durability Hazard Assessments Required Under Various Programs

Table 7. Zone Depressurization Limits for Selected Samples of Atmospherically Vented Appliances (Pressures of CAZ With Respect to Outdoors [Pa])

Table 8. Combustion Spillage Standards and/or Guidelines for Natural Draft Appliances.

Table 9. Results of Cold Vent Establishment Procedure Applied to Atmospheric Draft Appliances22

Table 10. WCD and Spillage Test Results

Table 11. Summary of Minimum IEQ and Durability Testing Recommendations for Use in Building

Unless otherwise indicated, all tables were created by NorthernSTAR. 


\section{Definitions}

$\mathrm{ACM}$

ANSI

ASTM

BPI

CAZ

$\mathrm{CDC}$

$\mathrm{CO}$

$\mathrm{COV}$

CVEP

EPA

HEPA

IEQ

IR

$\mu$

$\mu \mathrm{m}$

NFGC

NFPA

ODS

OSHA

$\mathrm{Pa}$

$\mathrm{pCi} / \mathrm{L}$

RESNET

RRP

VOC

WAP

WCD
Asbestos containing material

American National Standards Institute

American Society for Testing and Materials

Building Performance Institute

Combustion appliance zone

Centers for Disease Control and Prevention

Carbon monoxide

Coefficient of variation

Cold Vent Establishment Procedure

U.S. Environmental Protection Agency

High-efficiency particulate air (filter)

Indoor environmental quality

Infrared

micron

micrometer

National Fuel Gas Code

National Fire Protection Association

Oxygen depletion sensor

Occupational Safety and Health Administration

Pascal

Picocuries per liter

Residential Energy Services Network

Renovation, Repair and Painting Program Rule

Volatile organic compound

Weatherization Assistance Program

Worst case draft 


\section{Executive Summary}

Homeowners and occupants face indoor environmental quality and other hazards that can affect the durability of their homes. Some may be triggered or exacerbated by energy retrofitting and home renovations. Commonly cited hazards include carbon monoxide from combustion appliances, radon gas, and moisture accumulation that may promote mold growth and structural decay.

This report uses data from various sources to characterize the impact on human health and property damage of some of these hazards. Radon is believed to cause 15,000-22,000 deaths per year in the United States; carbon monoxide from all sources (except structure fires) causes about 450 deaths per year. Few data were found describing health effects or property damage specifically associated with moisture accumulation.

Many energy programs require testing that is intended to identify health, safety, and durability hazards before or after retrofitting. Established test procedures commonly include a battery of tests that are intended to screen combustion appliances for safe operation, and may include procedures for identifying gas leakage, moisture accumulation or mold growth, and in some cases, radon concentration. Considerable research indicates, however, that currently accepted test methods may have significant shortcomings for combustion safety, radon testing, and perhaps other hazards. These and other test methods can be improved, and some specific improvements are discussed.

The report provides guidance for testing to identify indoor environmental quality and building durability hazards in the context of energy retrofitting activities. It is intended to support the Building America goal of maintaining comfort, safety, and durability while reducing energy use. These recommendations are based on currently accepted test methods, with limited modifications, and as such are usable without further research or validation.

The report concludes that it is inappropriate to rely exclusively on one-time testing to identify and eliminate indoor environmental and durability hazards that may exist during retrofitting, or may develop at any later time. Instead, a variety of mechanisms, including education, construction standards, testing, and communication could be developed to provide a more robust approach to protecting home occupants.

The report also includes recommendations for further research. 


\section{Acknowledgments}

This report was prepared for the U.S. Department of Energy Building America program. Funding was provided by the National Renewable Energy Laboratory under contract KNDJ-0-40338-00. Additional funds were provided by the University of Minnesota, Initiative for Renewable Energy and the Environment, and Energy Center of Wisconsin.

The primary authors were Dan Cautley, senior project manager, John Viner, senior project manager, Melanie Lord, project manager, Energy Center of Wisconsin, and Mac Pearce, principal, McGregor Pearce Associates. 


\section{Introduction}

Remodeling or retrofitting a home, whether or not it is done with the intent of increasing energy efficiency, may result in increased exposure to indoor environmental and building durability hazards. Examples include carbon monoxide (CO) spillage from combustion appliances when air leakage is reduced, and structural decay of framing caused by water leakage around windows after replacement.

Retrofitting for energy efficiency may either increase or decrease specific hazards, depending on the circumstances. Tighter buildings mean contaminants released indoors will tend to accumulate to higher concentrations and thus increase occupant exposure. And reduced air leakage combined with increased insulation levels and decreased heating energy use mean less energy passes through enclosure systems, increasing the likelihood that moisture will accumulate to problematic levels. Reduced air leakage, on the other hand, may also help reduce exposure to contaminants or irritants, such as pollen, that are generated outdoors. A trend toward engineered ventilation systems may offset the contaminant concentration effects of increased airtightness.

This report discusses issues related to indoor environmental quality (IEQ) and building durability. These issues are important to contractors, program designers and administrators, policy makers, and researchers, and are directly relevant to the Building America program goal to develop techniques that can "improve efficiency of new and existing homes in each U.S. climate zone, while increasing comfort, safety, and durability" (EERE-BA 2011).

This report begins with a discussion of hazards in the context of home energy retrofitting. We use the term hazard as it is used in the occupational health field, to mean something that can harm a building or its occupants. ${ }^{1}$

Examples of hazards follow:

- CO spillage from combustion appliances, or CO production by unvented appliances

- Penetration of significant liquid water into structures

- Secondary tobacco smoke.

We consider hazards in two categories:

- Hazards to human health, termed IEQ hazards

- Hazards to the structural integrity of the building, termed durability hazards.

\footnotetext{
${ }^{1}$ A hazard is any source of potential damage, harm, or adverse health effects on something or someone under certain conditions. Risk is the chance or probability that a person will experience an adverse health effect if exposed to a hazard, or that property damage will occur. www.ccohs.ca/oshanswers/hsprograms/hazard risk.html
} 
Most hazards in both categories that are associated with energy retrofitting may also occur with general, nonenergy home renovations. ${ }^{2}$

The energy efficiency community recognizes the potential for increased hazard levels associated with retrofitting. It has developed a variety of tests intended to identify these risks and protocols for applying tests in retrofit projects (BPI 2010; RESNET 2010).

Examples include testing combustion appliances for proper venting operation, and inspecting building interiors for mold growth or other signs of moisture accumulation.

We can ask many questions about how best to reduce hazards associated with home retrofitting. The following questions are asked in this report:

- What IEQ and durability hazards are associated with the retrofitting and remodeling of homes?

- What incidence of human illness, injury, or death can be attributed to these hazards?

- What test methods and protocols currently guide risk identification?

- Do test methods - as currently used - effectively identify hazards as intended? What alternative methods can be used or might be developed?

- Should our approach to hazard identification be broadened beyond one-time testing, to lead to more robust identification and mitigation of hazards associated with home retrofitting?

Some readers may be particularly interested in certain sections.

- Section 2, Review of Hazards Related to Energy Retrofitting, is an introduction to hazards that may be associated with energy retrofitting in homes, including the effects of hazardous substances on human health, safety, and building durability.

- Section 3, Rates of Illness, Injury, and Death Associated With Hazards in the Home, characterizes the risks associated with the hazards, presenting data on annual rates of injuries, illnesses, deaths, and property damage from building-related hazards in the United States. This information can help put risk levels in context and make them more easily understandable, and may be of particular interest to researchers, program administrators, and policy makers.

- Section 4, Testing Protocols Currently in Common Use, provides an overview of IEQ and durability test requirements as currently required under various energy programs. This section focuses on Minnesota and Wisconsin, the location of the NorthernSTAR Building Amercia team.

- Section 5, IEQ and Durability Test Methods, discusses specific test methods in more detail. The section draws on published research that provides commentary on gaps and

\footnotetext{
${ }^{2}$ New construction may also result in unexpected IEQ and durability hazards. Much of our discussion in the context of retrofitting also applies to new construction.
} 
shortcomings in currently recognized test methods, and emphasizes combustion safety and radon testing. Section 5 should be of interest to those engaged in any aspect of IEQ and durability in homes.

- Sections 6, Testing Alternatives, offers suggestions for improvements to specific test methods or protocols.

- Section 7, A General Approach, suggests a revised approach to IEQ and durability testing that reduces the emphasis on one-time testing in homes in favor of a multifaceted approach that includes testing along with design, education, and other elements. This section should be of interest to program managers and policy makers. Bottom line recommendations for a practical, widely applicable set of tests for use in energy retrofitting appear in Section 7.3; these may be especially useful to contractors.

- Section 8 lists further research needs related to IEQ and durability testing, and will be of interest to researchers and policy makers.

This report draws heavily from published research and other published information such as testing protocols. The NorthernSTAR team did not perform any original field research to prepare this report. Many of the concepts related to improved approaches to testing originate with the authors, however, including much of the material in Sections 6, 7, and 8.

This report is not comprehensive, but focuses on combustion safety more than on other hazards. Many topics might be considered that this report does not address, including many chemical hazards for which the epidemiology or testing methods are lacking or incomplete, and materials that may be irritants to people with specific sensitivities. The law addresses work in the presence of lead and asbestos, and we place little emphasis on them, though evaluation of current standards would be a worthy topic for further work. We generally do not address specific methods of mitigating or reducing hazards that may be identified during retrofitting. We do not address contractor liability, which may be a major factor in encouraging the contracting community to adopt hazard identification protocols. 


\section{Review of Hazards Related to Energy Retrofitting}

Hazards related to energy retrofitting occur or change for a number of reasons:

- Tightening the building envelope to reduce air leakage may lead to spillage of combustion products from vented appliances.

- The reduction in overall ventilation rates caused by air sealing and installing direct vent appliances means that the concentration of any contaminants released in the home, and humidity levels, will likely increase.

- Decreased air leakage, increased insulation, and decreased heat loss through building envelopes reduce drying capacity in wall and roof systems.

- Changes in building envelope materials and construction may lead to moisture intrusion.

- Toxic or irritating substances may be used in retrofitting, or may be present in homes. These may be exposed or released during retrofitting.

A list of hazards that are commonly associated with energy-related work in homes, and some that are less likely to be related to energy work (e.g., dust mites, cockroaches, and secondhand smoke), follows. Most may also be factors in nonenergy remodeling of homes.

- $\mathrm{CO}$, oxides of nitrogen

- Formaldehyde (and other volatile organics)

- Radon and radium

- Exposure to molds

- Moisture accumulation

- Growth of decay fungi

- Dust mites, cockroaches, other asthma triggers

- Carpenter ants, termites

- Lead

- Asbestos

- Accumulation of flammable gases

- Fire

- Legionella bacteria

- Secondhand smoke.

In general, these hazards carry a direct risk to human health or structural durability. Some may also lead to outcomes that do not strictly fall into the health or durability categories, but are clearly negative. Such results may include odors and aesthetic degradation of building materials or furnishings. 


\subsection{Description of Hazards}

A more complete discussion of some hazards commonly associated with energy-related work in homes follows.

\subsubsection{Carbon Monoxide}

$\mathrm{CO}$ and oxides of nitrogen are produced in combustion; $\mathrm{CO}$ in particular is produced when a combustion process has insufficient oxygen or is incomplete for other reasons. $\mathrm{CO}$ is poisonous; according to the Occupational Safety and Health Administration (OSHA): "Carbon monoxide is an asphyxiant in humans. Inhalation of carbon monoxide causes tissue hypoxia by preventing the blood from carrying sufficient oxygen" (OSHA 2012).

Symptoms of acute exposure include headache, dizziness, nausea, and ultimately death. The effects of chronic exposure appear to be less well established. A recent review of medical literature indicates likely impairment from chronic low-level exposure, as well as impairment from nonfatal acute exposures (Yost 2012). According to OSHA (2012), "Repeated bouts of carbon monoxide poisoning may cause persistent signs and symptoms, such as anorexia, headache, lassitude, dizziness, and ataxia."

\subsubsection{Radon}

Exposure to radon increases the risk of lung cancer, and is thought to be its second-leading cause after smoking. Radon enters homes from the soil through foundation cracks and penetrations. Though radon is not generally deposited or absorbed in the lungs, its decay products are generally ionized and are more likely to adhere to — or be deposited in — the lungs, exposing lung tissue to the radiation from further decays (EPA 2009).

Radon and radium (which decays to form radon) are also found in groundwater. Only an estimated $1 \%-2 \%$ of radon in homes comes from drinking water, so this vector appears to present a much lower risk overall than radon entry directly from the soil (WDNR 2003; EPA 2011a).

\subsubsection{Molds}

Molds and mildews propagate by spores that are typically invisible to the naked eye. Mold spores are present in the air in most buildings and in natural environments. Most molds that grow in buildings require either liquid water or very high relative humidity (typically well above $80 \%$ ) at the surface on which they are growing. Various molds thrive at different ranges of temperatures, but many common varieties grow well across a range of conditioned space temperatures, as well as in unconditioned attics and basements.

Molds can present health problems when mold spores or other parts of the organisms are inhaled or come into contact with mucous membranes. Health effects include:

- Allergic responses, such as sneezing, irritation of nose, mouth or throat, nasal stuffiness, and itching eyes

- Asthma responses, including shortness of breath, coughing, and chest tightness 
- Hypersensitivity pneumonitis, which involves inflammation of the lungs in people who have developed an immune system response to inhaled organic dusts. Symptoms can include shortness of breath, coughing, chills, fever, and fatigue.

Some molds produce toxins that may carry other risks to exposed individuals, but there is a lack of agreement on whether exposure to these toxins carries health risks that are significantly different than those associated with exposure to other molds (CDC 2011).

The growth of molds in buildings requires mold spores, a surface that provides nutrients, elevated moisture levels, and appropriate temperatures. The availability of moisture most often determines whether molds grow in buildings (CDC 2011).

\subsubsection{Gas Leakage}

Leakage of fuel gas (e.g., natural gas or propane) can lead to fires or explosions with potentially devastating consequences to occupants and to property.

\subsubsection{Lead}

Lead can enter the body through ingestion and inhalation. Inhalation is most likely among workers who are sanding, melting, or burning lead-based materials. Ingestion is the common route of entry for children who are exposed to lead dust from windows and other finished wood in older homes. According to the U.S. Environmental Protection Agency (EPA 2011b), exposure to lead can have health effects in children, including:

- Brain and nervous system damage

- Behavior and learning problems, such as hyperactivity

- Slowed growth

- Hearing problems

- Headaches.

Adult men and women exposed to lead can experience:

- Reproductive problems

- High blood pressure and hypertension

- Nerve disorders

- Memory and concentration problems

- Muscle and joint pain.

The United States Consumer Product Safety Commission banned the use of lead in paint on September 2, 1977 (CPSC 1977). Lead paint is thought to be still common in older homes. 


\subsubsection{Asbestos}

Inhaled asbestos has been established as increasing the risk of lung cancer, mesothelioma (a cancer of the chest lining and the abdominal cavity), and asbestosis (a noncancerous scarring of lung tissue) (NCI 2009). Asbestos was used in various insulating materials (including as an incidental contaminant in some vermiculite), textured paints and patching materials, cementbased siding, and other materials.

The EPA banned most asbestos uses on July 12, 1989, but the regulation was overturned in court; thus, some products may be still manufactured with asbestos (EPA 2010a, 2010b).

\subsubsection{Formaldehyde}

Formaldehyde is recognized as an irritant to mucous membranes in the eyes and respiratory tract, and is suspected of being carcinogenic (OEHHA 2008).

Sources of formaldehyde include pressed wood products manufactured using urea formaldehyde resins, such as particle board, some plywood paneling, and especially medium-density fiberboard (used in cabinets and furniture), some other adhesives, and combustion (including smoking) (EPA 2011c).

\subsubsection{Moisture}

Moisture accumulation, in addition to its association with mold growth, can lead to degradation of building materials through fungal decay, insect attack, staining, and peeling of paint. Wood generally decays only if it has a moisture content above the fiber saturation point (about $30 \%$ water by weight), beyond which free water is available to support the fungi that cause decay. This is well above equilibrium moisture levels for wood in buildings that are protected from direct exposure to weather or other moisture sources.

\subsubsection{Insects}

A variety of insects may attack wood; termites are the most destructive. A number of termite species live in the United States, and although all require some moisture to survive, some may inhabit wood that is quite dry. The best way to prevent termite damage is to prevent the insects from gaining access to susceptible building materials (FPL 2010).

\subsubsection{Particulates}

Particulate matter is described by size. The term inhalable coarse particles is commonly (but not universally) used to designate particles of 2.5-10 $\mu \mathrm{m}$, fine particles for those $0.1-2.5 \mu \mathrm{m}$, and ultrafine particles for material smaller than $0.1 \mu \mathrm{m}$. Particulate matter across these size ranges can be drawn into the lungs, where some particles may be deposited and have adverse health effects through chemical, biological, and physical processes. EPA lists the following health effects of particle pollution (EPA 2011f):

- Increased respiratory symptoms, such as irritation of the airways, coughing, and difficulty breathing

- Decreased lung function

- Aggravated asthma 
- Chronic bronchitis

- Irregular heartbeat

- Nonfatal heart attacks

- Premature death in people with heart or lung disease. 


\section{Rates of IIIness, Injury, and Death Associated With Hazards in the Home}

The incidence of injury, illness, and death associated with exposures to hazards has been reported for many of the hazards discussed in Section 2. Table 1 summarizes the reported and estimated annual rates of injury and death in the United States. It includes several additional hazards for comparison that are not normally associated with home retrofitting (e.g., secondhand smoke) or that occur outside the home (auto accidents). Sources for values shown are listed in Appendix A. Figure 1 shows the estimated annual number of deaths from various causes graphically.

Table 1. Illnesses, Injuries, and Deaths Attributable to Home-Related Hazards in the United States ${ }^{a, b}$

\begin{tabular}{|c|c|c|c|}
\hline Risk & $\begin{array}{c}\text { Typical Annual Number } \\
\text { of Illnesses or Injuries } \\
\text { (U.S.) }\end{array}$ & $\begin{array}{l}\text { Typical Annual } \\
\text { Deaths } \\
\text { (U.S.) }\end{array}$ & $\begin{array}{c}\text { Annual Property } \\
\text { Damage } \\
(\$)\end{array}$ \\
\hline Allergens & $\begin{array}{l}>50 \text { million } \\
\text { (half the population tests } \\
\text { positive for one or more } \\
\text { allergens) }\end{array}$ & $\mathrm{NA}^{\mathrm{d}}$ & NA \\
\hline Asbestos $^{c}$ & $\begin{array}{c}200,000 \\
\text { (individuals currently } \\
\text { living with asbestosis) }\end{array}$ & 10,000 & NA \\
\hline Asthma & $\begin{array}{c}15 \text { million } \\
\text { (physician office and } \\
\text { hospital outpatient visits) }\end{array}$ & 4,000 & NA \\
\hline CO & 20,600 exposures per year & 450 & NA \\
\hline Fires & 12,900 & 2,650 & $\$ 7.1$ billion \\
\hline $\begin{array}{c}\text { Fungal Decay } \\
\text { (Includes Termite } \\
\text { Damage) }\end{array}$ & NA & NA & $\begin{array}{c}\$ 5 \text { billion } \\
\text { (estimated termite } \\
\text { damage) }\end{array}$ \\
\hline Lead & $\begin{array}{l}29,000 \\
\text { (children younger than } 6 \\
\text { with confirmed elevated } \\
\text { blood lead levels) }\end{array}$ & Limited data ${ }^{\mathrm{e}}$ & NA \\
\hline Radon & NA & $\begin{array}{c}15,000-22,000 \\
(2,900 \text { among } \\
\text { nonsmokers })\end{array}$ & NA \\
\hline Secondhand Smoke & $\begin{array}{c}>150,000 \\
\text { (illness in children) }\end{array}$ & $\begin{array}{c}50,000 \\
\text { (all ages) }\end{array}$ & NA \\
\hline $\begin{array}{c}\text { Volatile Organic } \\
\text { Compounds (VOCs) } \\
\text { Including } \\
\text { Formaldehyde }\end{array}$ & Limited data & Limited data & NA \\
\hline
\end{tabular}




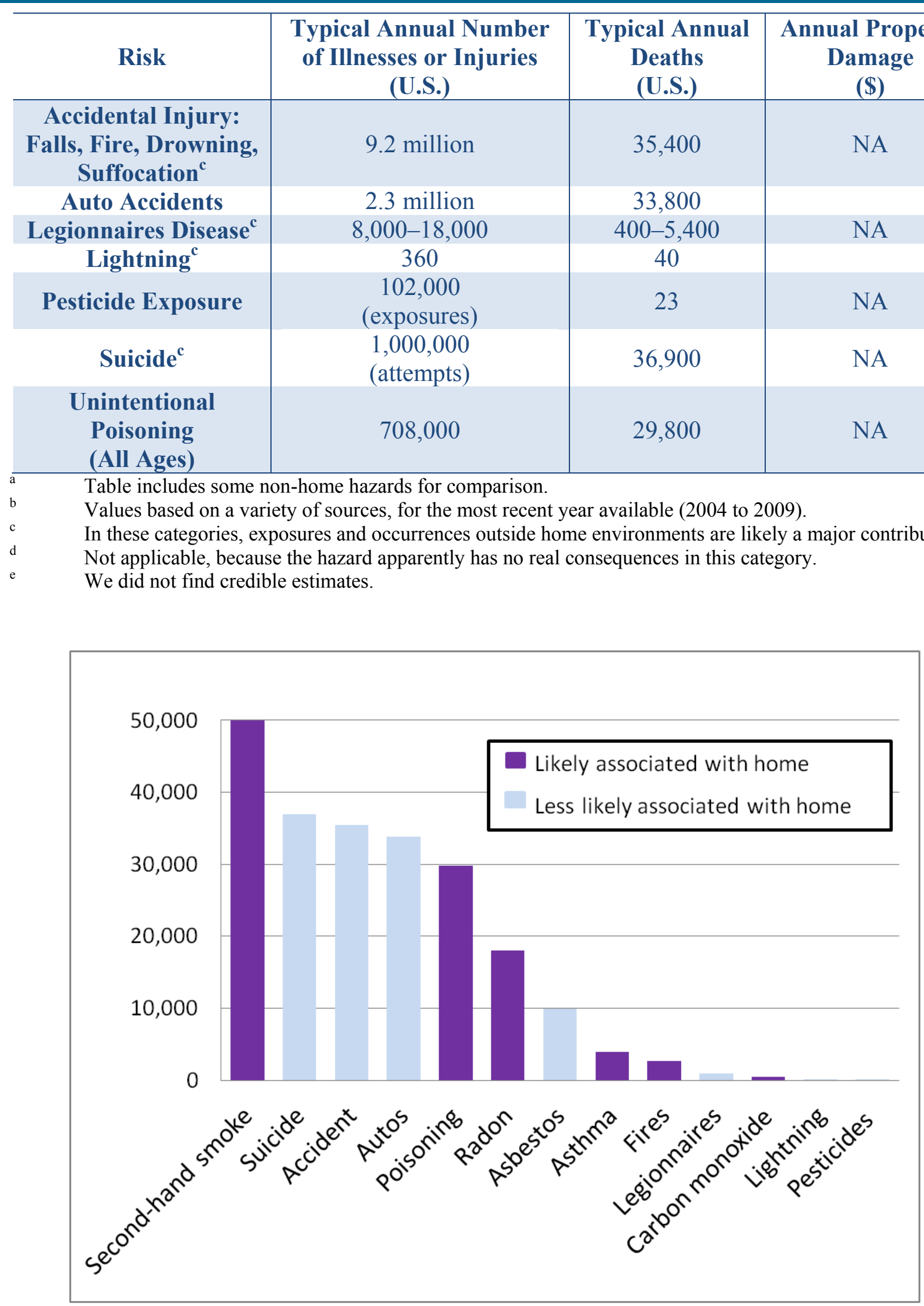

Figure 1. Estimated annual number of U.S. deaths from various causes 
The following sections discuss some of these hazards individually.

\subsection{Carbon Monoxide}

The Centers for Disease Control and Prevention (CDC) estimates an average of 20,636 unintentional, nonfire-related exposures to CO occur in the United States every year (CDC 2007, 2008). These exposures result in an estimated 15,000 emergency department visits and approximately 450 unintentional deaths.

In 2007 (the most recent year for which statistics are available) about 183 deaths (nationally) were caused by $\mathrm{CO}$ exposure from consumer products, which include appliances permanently installed in homes. Table 2 shows the estimated annual number of deaths from CO produced by various categories of consumer products, based on data gathered in 2005-2007.

Table 2. Estimated Annual CO Poisoning Deaths Caused by Fuel-Burning Consumer Products, 2005-2007

\begin{tabular}{|c|c|c|}
\hline Consumer Product Category & & $\begin{array}{c}\text { Estimated Annual } \\
\text { U.S. Deaths }\end{array}$ \\
\hline Heating Systems (All Fuels) Includes: & \\
Furnaces (All Fuels) & 26 & \\
Portable Heaters (All Fuels) & 19 & 57 \\
Wall/Floor Furnaces (All Fuels) & 5 & \\
Room/Space Heaters (All Fuels) & 6 & \\
$\quad$ Unspecified & 1 & 4 \\
Gas Ranges or Ovens & & 4 \\
\hline Gas Water Heaters (Liquefied Petroleum, & & 1 \\
Natural Gas, and Unspecified) & 91 \\
\hline Fireplace/Chimney (Gas or Wood) & \\
Engine-Driven Generators and Tools & 10 \\
\hline Charcoal Grills, Fuel-Fired Grills and Camp Stoves & 184 \\
Other (Including Multiple Products) \\
Total
\end{tabular}

Table 3 shows the percentage of nonfatal, nonfire-related, unintentional exposures to $\mathrm{CO}$ by likely sources, based on a sample of 778 cases recorded in National Electronic Injury Surveillance System All Injury Program (CDC 2005). Sixty-four percent of the CO exposures that resulted in emergency room visits occurred in homes (CDC 2005). ${ }^{3}$ Some studies indicate that a high percentage of $\mathrm{CO}$ exposures from motor vehicle exhaust are associated with stationary vehicles, a small percentage of which appears to be the result of a vehicle left running in a garage (CDC 1996; Hampson 2011).

\footnotetext{
${ }^{3}$ Limitations on these results include: information on sources of $\mathrm{CO}$ exposure and symptoms of persons with $\mathrm{CO}$ poisoning was missing for a substantial percentage of cases, and estimates are based on persons treated in emergency rooms only (do not include those treated in outpatient settings or not treated at all).
} 
Table 3. Unweighted Number of Nonfatal, Unintentional, Nonfire-Related CO Exposures by Source, 2001-2003

\begin{tabular}{|c|c|}
\hline Source & Percent of Exposures \\
\hline Furnace & 18.5 \\
\hline Stove/Gas Range & 4.9 \\
Gas Water Heater & 4.2 \\
Space Heater & 1.9 \\
Generators & 2.8 \\
Motor Vehicle & 9.1 \\
\hline Other or Unknown & 58.6 \\
Total & 100.0 \\
\hline
\end{tabular}

One issue with $\mathrm{CO}$ exposure that is outside the realm of testing protocols in homes presents an opportunity for home occupant education about combustion equipment and power outages from hurricanes and other storms. CDC data on CO poisoning show spikes in fatal and nonfatal exposure at the time four major hurricanes hit Florida in 2004 (CDC 2004). Analysis determined that misplacements of portable, gasoline-powered generators were responsible for nearly all the exposures. A spike in CO exposure was reported in Connecticut after a late October 2011 snowfall caused power outages in the Northeast (USA Today 2011).

\subsection{Residential Structure Fires}

Every year, home structural fires cause about 2,650 civilian deaths, 12,890 civilian injuries, and $\$ 7.1$ billion in property damage. The leading cause of home structure fires is cooking equipment (NFPA 2011). Table 4 shows the estimated number of residential fires in 2008 by select causes, number of injuries, number of deaths, and property loss (CPSC 2011).

Table 4. Estimated Number of Residential Fires in 2008

\begin{tabular}{|c|c|c|c|c|}
\hline Cause & Number & Deaths & Injuries & $\begin{array}{c}\text { Property Loss } \\
\text { (\$ millions) }\end{array}$ \\
\hline Local Fixed Heater & 4,900 & 60 & 360 & 148.3 \\
Portable Heater & 1,900 & 100 & 210 & 87.4 \\
Central Heating & 1,200 & $<10$ & 50 & 37.9 \\
\hline Fireplace, Chimney, Chimney Connector & 27,200 & 10 & 80 & 147.6 \\
Water Heater & 2,300 & 10 & 130 & 62.3 \\
\hline Air Conditioning & 1,000 & $<10$ & 20 & 24.4 \\
\hline Total Heating and Cooling Equipment ${ }^{4}$ & 56,300 & 220 & 1,050 & 649.0 \\
Range/Oven & 14,600 & 130 & 1,410 & 300.8 \\
Gas & & & & \\
Electric & 2,300 & 40 & 150 & 45.2 \\
All Other Cooking & 12,300 & 90 & 1,270 & 255.2 \\
Total Cooking Equipment ${ }^{4}$ & 5,500 & & 140 & 157.5 \\
Installed Wiring & 149,100 & 140 & 3,560 & 483.9 \\
Cord, Plug & 5,100 & 120 & 100 & 210.5 \\
\hline
\end{tabular}

\footnotetext{
${ }^{4}$ Includes other equipment not listed. Subtotals do not necessarily add to heading totals because of the inclusion of "confined fire" estimates for which the type of equipment involved cannot be determined.
} 


\begin{tabular}{|c|c|c|c|c|}
\hline Cause & Number & Deaths & Injuries & $\begin{array}{c}\text { Property Loss } \\
\text { (\$ millions) }\end{array}$ \\
\hline Receptacle, Switch & 1,400 & 10 & 20 & 41.2 \\
\hline Lighting & 2,200 & 10 & 130 & 85.0 \\
\hline Total Electrical Distribution ${ }^{4}$ & 12,100 & 210 & 420 & 476.5 \\
\hline Clothes Dryer & 6,800 & 40 & 230 & 91.5 \\
\hline Washing Machine & 300 & $<10$ & $<10$ & 2.9 \\
\hline Refrigerator/Freezer & 900 & $<10$ & 10 & 24.6 \\
\hline Cigarette, Other Tobacco Products & 11,100 & 550 & 1,120 & 435.3 \\
\hline
\end{tabular}

\subsection{Asthma}

Approximately 25 million people in the United States (almost 7 million of whom are children) have asthma. EPA research has shown that exposure to dust mites and ozone and particle pollution can cause asthma; exposure to secondhand smoke can cause asthma in preschool-aged children. Several of these factors, including dust mites, cockroaches, pet dander, secondhand smoke, ozone, and particle pollution, can trigger asthma attacks as well (EPA 2011d).

Each year in the United State there are approximately:

- 13 million asthma attacks

- 15 million asthma-related physician office and hospital outpatient visits

- 4,000 asthma-related deaths.

In 2008, children in the United States were absent from school for an estimated 14.4 million days because of asthma; adults lost 14.2 million workdays. Asthma accounts for $\$ 56$ billion in health care costs annually (EPA 2011d; ALA 2007).

\subsection{Radon}

Scientists agree that long-term exposure to radon increases the risk of developing lung cancer in humans. Although it represents a much smaller risk than cigarette smoking (the most common cause of lung cancer), the National Cancer Institute estimates that annually 15,000-22,000 lung cancer deaths in the United States are associated with radon exposure. This estimate is based on combined data from studies of miners exposed to relatively high levels of radon and of others exposed to lower levels in homes (NCI 2011).

\subsection{Other Risks}

Many other risks may be associated with energy retrofitting of homes. Examples include:

- Oxides of nitrogen produced in combustion

- Chemicals associated with construction materials and furnishings (VOCs and semivolatile organic compounds, halogenated flame retardants, etc.)

- Safety hazards present during construction.

Discussion of these hazards is beyond the scope of this report. 


\section{Testing Protocols Currently in Common Use}

In attempting to address hazards associated with retrofitting while performing energy audits and in specifying or performing retrofit work, many energy efficiency program operators rely on the work of two major national organizations, the Residential Energy Services Network (RESNET) and the Building Performance Institute (BPI). Each has established building performance standards that include language addressing certain hazards, and has developed test protocols for meeting those standards.

Table 5 shows hazards addressed in RESNET and BPI performance standards, and indicates the names of test procedures where appropriate. "General requirement" means the standard addresses a hazard in general terms, but does not describe a specific test method. As evident from the table, the greatest emphasis in IEQ/durability testing by these organizations is on combustion safety. RESNET and BPI standards are available online at www.resnet.us/standards and http://bpi.org/standards.aspx.

Table 5. Written Standards to Assess Risk Before Work Begins

\begin{tabular}{|c|c|c|c|}
\hline Hazard & Test Procedure & RESNET & BPI \\
\hline \multirow{7}{*}{ CO Exposure } & Ambient $\mathrm{CO}$ & Yes & Yes \\
\hline & $\begin{array}{c}\text { Combustion appliance zone (CAZ) } \\
\text { depressurization }\end{array}$ & Yes & Yes \\
\hline & Vent spillage under worst case scenario & Yes & Yes \\
\hline & Worst case draft (WCD) pressure & Yes & Yes \\
\hline & Natural draft pressure & Yes & Yes \\
\hline & $\mathrm{CO}$ in the flue & Yes & Yes \\
\hline & Gas oven $\mathrm{CO}$ & Yes & Yes \\
\hline Gas Leakage & General requirement & Yes & Yes \\
\hline Fungal Decay & General requirement & Yes & Yes \\
\hline Mold & General requirement & Yes & Yes \\
\hline Lead & General requirement & Yes & Yes \\
\hline Asbestos & General requirement & Yes & Yes \\
\hline Exterior Bulk Water Entry & General requirement & Yes & Yes \\
\hline Interior Humidity Control & General requirement & Yes & Yes \\
\hline $\begin{array}{c}\text { Formaldehyde and Other } \\
\text { VOCs }\end{array}$ & No requirements & - & - \\
\hline Radon & EPA Guidelines for Radon Testing & No & Yes \\
\hline
\end{tabular}

Test procedures are discussed in more detail in the Section 4.1. Readers unfamiliar with the test procedure names may want to read that section first.

Many voluntary energy efficiency programs have created their own protocols, often drawing heavily from RESNET or BPI protocols or procedures, and with a similar emphasis on combustion safety testing to reduce $\mathrm{CO}$ hazards. Moisture and radon are sometimes mentioned, but often with no guidance on specific test methods, leaving contractors to determine when and how to evaluate such risks. 
Table 6 shows the test procedures used by several energy programs in the upper Midwest. A "yes" or "no" answer indicates whether or not the particular program calls for assessment through the use of specific test procedures, visual observations, or homeowner interviews. This table should be viewed as a summary, and it does not compare the thoroughness of the procedures used in each program. In some cases, a specific test is called for based on the results of other tests or procedures; for example, a natural draft pressure spillage test may be called for if a combustion system fails under WCD conditions. Lead and asbestos are special cases in which federal regulations apply. We believe the Wisconsin Home Performance with ENERGY STAR column is representative of many other energy programs that have adopted BPI standards. 
Table 6. IEQ and Durability Hazard Assessments Required Under Various Programs

\begin{tabular}{|c|c|c|c|c|c|}
\hline & & \multicolumn{4}{|c|}{ Programs/Organizations } \\
\hline Hazard & $\begin{array}{l}\text { Testing Procedures } \\
\text { and/or Inspections }\end{array}$ & $\begin{array}{c}\text { Wisconsin Home } \\
\text { Performance with } \\
\text { ENERGY STAR } \\
\text { Program }\end{array}$ & $\begin{array}{l}\text { Wisconsin Low } \\
\text { Income } \\
\text { Weatherization } \\
\text { Program }\end{array}$ & $\begin{array}{c}\text { City of } \\
\text { Minneapolis } \\
\text { Community } \\
\text { Energy Services } \\
\text { Program } \\
\end{array}$ & $\begin{array}{c}\text { Minnesota } \\
\text { Low Income } \\
\text { Weatherization } \\
\text { Program }\end{array}$ \\
\hline CO Exposure & $\begin{array}{c}\text { Ambient CO } \\
\text { CAZ depressurization } \\
\text { Vent spillage under } \\
\text { worst case scenario } \\
\text { WCD pressure } \\
\text { Natural draft pressure } \\
\text { CO in the flue } \\
\text { Gas oven CO }\end{array}$ & $\begin{array}{l}\text { yes } \\
\text { yes } \\
\text { yes } \\
\text { yes } \\
\text { yes } \\
\text { yes } \\
\text { yes }\end{array}$ & $\begin{array}{l}\text { yes } \\
\text { yes } \\
\text { yes } \\
\text { yes } \\
\text { no } \\
\text { yes } \\
\text { yes }\end{array}$ & $\begin{array}{c}\text { yes } \\
\text { yes } \\
\text { yes } \\
\text { yes } \\
\text { no } \\
\text { yes } \\
\text { no }\end{array}$ & $\begin{array}{l}\text { yes } \\
\text { yes } \\
\text { yes } \\
\text { yes } \\
\text { no } \\
\text { yes } \\
\text { yes }\end{array}$ \\
\hline Gas Leakage & & yes & yes & no & yes \\
\hline Fungal Decay & Inspection? & yes & yes & no & yes \\
\hline Mold & Inspection? & yes & yes & no & yes \\
\hline Lead & $\begin{array}{l}\text { Federal/state } \\
\text { regulations }\end{array}$ & yes & yes & no & yes \\
\hline Asbestos & $\begin{array}{l}\text { Federal/state } \\
\text { regulations }\end{array}$ & yes & yes & yes & yes \\
\hline $\begin{array}{l}\text { Exterior Bulk } \\
\text { Water Entry }\end{array}$ & Inspection? & yes & yes & no & $\begin{array}{c}\text { no (yes if } \\
\text { obvious signs } \\
\text { exist) }\end{array}$ \\
\hline $\begin{array}{c}\text { Interior } \\
\text { Humidity } \\
\text { Control }\end{array}$ & Inspection? & yes & yes & no & $\begin{array}{l}\text { no (yes if } \\
\text { obvious signs } \\
\text { exist) }\end{array}$ \\
\hline $\begin{array}{l}\text { Formaldehyde } \\
\text { and Other VOCs }\end{array}$ & Inspection? & no & no & no & no \\
\hline Radon & & no & no & no & no \\
\hline
\end{tabular}




\subsection{Test in, Test out Concept}

The concept of "test in, test out" is sometimes cited in home performance protocols. The idea of performing IEQ and durability testing both before and after retrofitting may have started as a requirement under some voluntary energy programs. In 2005, BPI released the technical standard for Building Analyst Professional (BPI 2005), which included explicit requirements for testing before and after work is performed:

When air sealing, enclosed cavity insulation representing $15 \%$ or more of the total building shell area, or sealing of the ducts outside the thermal envelope are recommended, the work scope must include pre and postinstallation blower door tests.

A preliminary and post-installation safety inspection of all combustion appliances must be completed whenever changes to the building envelope and/or heating system are part of the work scope.

Similarly, in 2010 RESNET released interim guidelines for combustion safety testing (RESNET 2010), which call for pre- and postwork combustion appliance testing when any work affecting the enclosure, duct tightness, or building pressures is specified.

\subsection{Indoor Environmental Quality and Durability Testing Outside Organized Energy Programs}

In our experience, when home remodeling and energy retrofitting are performed outside the scope of established energy efficiency programs or low-income weatherization programs, very limited IEQ or durability evaluation is typically performed. Formal combustion safety testing procedures, for example, require specific skills and tools that most contractors do not have. Identification and appropriate treatment of lead and asbestos may be exceptions, based on federal requirements.

The home improvement industry does have some incentive to identify hazards even marginally associated with their work, in part because contractors may be held liable for problems identified during or after completion of work, even if they did not cause the problem. It is our experience that professional contractors will often follow an informal process in calling attention to- or even taking responsibility for-problems discovered during the course of work.

Contractors may also address obvious problems or problems brought to their attention by homeowners, without formal testing. For example, an HVAC contractor may attempt to address a perceived humidity problem by installing new equipment. 


\section{Indoor Environmental Quality and Durability Test Methods}

Following are descriptions of test methods that address some of the risks and hazards in homes.

\subsection{Combustion Safety Testing}

Testing for the proper operation of combustion appliance venting under various conditions, and testing for $\mathrm{CO}$ production or release, are often called combustion safety testing. Such testing is often applied to vented combustion appliances (with some exceptions for appliances of different vent types); CO tests are also often applied to unvented heating and cooking appliances. Specific tests that may be part of a protocol include:

- CAZ worst case depressurization

- Vent spillage under WCD

- Vent spillage under normal operating conditions

- Cold vent establishment

- Draft pressure at steady-state operating conditions, under WCD or normal pressure operation

- CO production (vented and unvented appliances).

An overview of these and other related methods can be found in "Standard Guide for Assessing Depressurization-Induced Backdrafting and Spillage from Vented Combustion Appliances" (ASTM 1998) and "Combustion Safety Test Procedure for Vented Appliances" (BPI 2012). See also Appendix B for a discussion of venting pressures.

\subsubsection{Combustion Appliance Zone Worst Case Depressurization}

CAZ depressurization (the pressure within the building zone containing combustion appliances as measured relative to pressure outside the building) provides one measure of forces that tend to cause combustion products to spill from an appliance into the interior zone, rather than flowing out the vent system. Depressurization is induced by operating exhaust fans, clothes dryers, and other systems, including HVAC blowers (which may either increase or decrease pressure in the CAZ, depending on the location of leaks in the system and building). Some procedures call for measuring the pressure difference of the CAZ with respect to outdoor pressure before performing the worst-case test, and subtracting this baseline pressure from the maximum induced pressure with fans operating. WCD refers to the greatest level of depressurization obtained with this test.

Operation of attic exhaust fans is generally called for (if mentioned at all) in WCD, as they are widely recognized to generally depressurize interior spaces to some degree. Operation of woodburning stoves and fireplaces is never called for (it would be impractical and possibly dangerous), but some procedures suggest operating a portable camping stove in a fireplace to induce a draft, and others (e.g., RESNET 2010) call for operating a blower door at $300 \mathrm{cfm}$ as a proxy for fireplace operation. Table 7 shows some depressurization limits used in current BPI and RESNET standards for a select sample of atmospherically vented appliances. 
Table 7. Zone Depressurization Limits for Selected Samples of Atmospherically Vented Appliances (Pressures of CAZ With Respect to Outdoors [Pa])

\begin{tabular}{c|c|c}
\hline Appliance Type & BPI & RESNET \\
\hline Stand-Alone Furnace or Boiler & -5 & -5 \\
Orphaned Water Heater & -2 & -5 \\
\hline Furnace or Boiler Commonly Vented With Water Heater & -3 & -5 \\
\hline
\end{tabular}

\subsubsection{Vent Spillage Tests}

Vent spillage refers to the escape of combustion products through the draft hood opening into the appliance zone (room). Spillage may include any fraction of the total combustion products. These tests most often include a measurement of the time from firing to the end of spillage, and pass/fail standards are written in terms of the time.

Vent flow and spillage are heavily influenced by vent temperatures, and some protocols implicitly assume - or explicitly call for — starting the test with a cool vent, though none seem to define what that means. ASTM E1998, for example, calls for cooling of the vent after testing one appliance and before testing a second appliance on the same vent system, and states that "masonry chimneys will take a considerably longer time to cool than metal chimneys" (ASTM 1998). When two appliances connected to a single venting system are to be tested, some procedures call for testing the appliance with the smaller fuel input first, then firing and testing the second appliance while the first is still operating.

Vent spillage under WCD refers to a test performed while the appliance zone is depressurized as described above. Vent spillage under normal operating conditions refers to the spillage of combustion products during operation without intentional depressurization. The test described in ASTM E1998 as the "Appliance Backdrafting Test" (ASTM 1998) is similar to the BPI spillage test.

The Cold Vent Establishment Procedure (CVEP) calls for depressurizing the CAZ to a level of 10-15 Pa below outdoor pressure, firing the appliance, and slowly relaxing depressurization until drafting begins. This provides an estimate of the maximum depressurization the appliance as installed can overcome in developing proper draft, regardless of the depressurization possible in the tested home. As such, test results can provide useful information on the behavior of typical appliances and their vent systems, independent of the homes in which they are installed.

Various procedures set a limit on spillage of 1-5 min. Spillage beyond this limit is considered a failure. The BPI 101 Home Energy Auditing Standard (BPI 2010), for example, states: "If a combustion appliance spills for longer than 1 minute, the audit report shall specify measures to mitigate spillage."

In contrast, Annex G of the 2012 Edition of the National Fuel Gas Code (NFGC), "Recommended Procedure for Safety Inspection of an Existing Appliance Installation"

\footnotetext{
${ }^{5}$ A clarification issued by BPI in December 2011 states that a standalone water heater connected to an oversized venting system is to be considered an "orphaned" water heater and subject to the value shown in the table; a standalone water heater connected to a properly sized vent is allowed a CAZ depressurization of $-5 \mathrm{~Pa}$ (BPI 2011).
} 
recommends testing for spillage after 5 min (NFPA 2012). RESNET draft standards also call for spillage testing after 5 min of operation, and states in Chapter 8 section 807.12: "Turn on vented combustion appliance with the smallest Btu capacity. Operate appliance for 5 minutes then measure $\mathrm{CO}$ levels according to the $\mathrm{CO}$ test procedure below, and check appliance draft using a smoke pencil at the draft diverter."

Table 8. Combustion Spillage Standards and Guidelines for Natural Draft Appliances

\begin{tabular}{c|c|c|c|c|c}
\hline & NFPA* NFGC $^{*}$ & BPI & RESNET & $\begin{array}{c}\text { WI - } \\
\text { WAP* }\end{array}$ & $\begin{array}{c}\text { MN - } \\
\text { WAP }^{\mathbf{6}}\end{array}$ \\
\hline $\begin{array}{c}\text { Allowable } \\
\text { Spillage Time }\end{array}$ & $5 \mathrm{~min}$ & $1 \mathrm{~min}$ & $5 \mathrm{~min}$ & $1 \mathrm{~min}$ & $30 \mathrm{~s}$ \\
\hline
\end{tabular}

* National Fire Protection Association

** Weatherization Assistance Program

An alternative spillage test procedure developed under the sponsorship of Natural Resources Canada and Canada Mortgage and Housing Corporation (CMHC) uses measured carbon dioxide concentration in a test room along with fuel input rate to provide a quantitative measure of spillage volumes under controlled negative pressure conditions (CMHC 2005). The project report discusses use of the procedure only with appliances that are not atmospherically vented and under exposure to depressurization of $50 \mathrm{~Pa}$, but the procedure appears to be applicable to appliances with other vent configurations and under other pressure conditions.

\subsubsection{Carbon Monoxide Production}

Some test procedures require measurement of $\mathrm{CO}$ concentration in combustion products and observation of $\mathrm{CO}$ levels in the CAZ during testing. For example, BPI standards state that energy auditors should call for servicing of an appliance if the $\mathrm{CO}$ concentration in undiluted flue gas (before mixing with room air at the draft hood) is greater than $100 \mathrm{ppm}$ uncorrected or $200 \mathrm{ppm}$ air-free (BPI 2010). ${ }^{7}$

Some procedures additionally call for monitoring the $\mathrm{CO}$ concentration in the zone or room where combustion testing is being performed, and commonly require discontinuation of testing if the $\mathrm{CO}$ concentration exceeds $35 \mathrm{ppm}$.

\subsubsection{Unvented Appliances}

Some test procedures are available for unvented fuel-fired appliances, though these often lack the detail of procedures for testing vented appliances. BPI, for example, calls for measuring the CO production of gas ovens, but does not mention cooktop burners (BPI 2010). BPI and others call for testing of ovens by inserting the probe of a $\mathrm{CO}$ meter or combustion analyzer into the exhaust vent of the oven. Experience shows that the CO concentration in an oven vent is often not uniform, and may be very different at one end of the vent than the center or other end. Some protocols call for sampling at the center of the vent (Karg 2001); others are silent on the topic.

\footnotetext{
${ }^{6}$ MWX90 - Minnesota Low Income Weatherization Procedures for the 1990s.

${ }^{7}$ Air-free refers to the $\mathrm{CO}$ concentration corrected for excess air ratio. It is effectively the concentration that would be observed if no excess air were present.
} 
Karg (2009) has provided some guidance for the measurement of CO production by cooktop burners, but otherwise little is available.

ANSI standard Z21.1 establishes limits for CO production of unvented space heaters at $200 \mathrm{ppm}$ air-free, and gas ovens at $800 \mathrm{ppm}$ air-free after a warmup period (ANSI 2010). BPI sets a limit of 200 ppm uncorrected or 400 ppm air-free for gas ovens; RESNET uses a limit of $200 \mathrm{ppm}$ uncorrected with no reference to an air-free value (RESNET 2010).

\subsubsection{Gas Leakage and Other Identification of Combustibles}

Some standards require that gas piping be inspected for leakage. BPI-101 states "Test for gas leakage at connectors of natural gas and propane piping systems. The report shall specify repair for leaks and replacement for hazardous or damaged gas connectors" (BPI 2010).

RESNET identifies calls for evacuation of the home and notification of appropriate authorities if there is a "noticeable odor indicating gas buildup" (RESNET 2010), but none of the procedures we reviewed provide quantitative guidance for differentiating between leaks that should merely be repaired from those that should trigger an immediate call for repair or evacuation.

RESNET also specifically calls for checking the CAZ for flammable or explosive materials in preparation for combustion safety testing.

Flammable gas detectors (often called "sniffers") are available from many manufacturers.

\subsubsection{Evaluation of Combustion Safety Test Methods}

A number of research projects have evaluated combustion safety test methods.

CMHC conducted a study in the mid-1980s that used heat-sensitive material mounted near venting systems to identify homes with vent spillage (CMCH 2004). Ten percent of the 606 gasheated homes investigated had significant spillage on at least one occasion during the test period. (A larger fraction of a smaller number of oil-heated homes also experienced spillage.) In a follow-up study, 16 homes identified as spillage-prone were monitored in more detail. The monitoring system was designed to observe spillage continuously, and was operated for 14-35 days in individual homes, for a total of 322 days of data. The results are summarized here:

Considering that the houses monitored were pre-selected to be those in which spillage incidents were thought to have occurred, remarkably few actually had significant spillage events. Of the sample 16 houses, 9 showed no spillage activity during the monitoring period. Two houses, which were oil-heated, had brief, infrequent periods where spillage was detected, consistent with the "startup puffs" expected with a powered burner. Five gas-heated houses indicated significant spillage incidences (a significant spillage event was defined as 10 seconds of spillage for a gas-heated house and 5 seconds for an oil-heated house). In one gasheated house, the spillage was almost exclusively driven by the fireplace. In another, the spillage seemed driven by other exhaust appliances, notably exhaust fans. In the remaining three gas-heated houses, spillage occurred regularly even in the absence of aggravating conditions. 
The report states that spillage episodes in the absence of depressurization factors suggest that poor chimney performance is a significant contributor and requires further exploration.

It should be emphasized that the Canadian study above classified events lasting only 5 or $10 \mathrm{~s}$ as spillage. Other observers have found spillage of brief duration to be remarkably common.

In detailed monitoring of 10 residential gas water heaters, the Energy Center of Wisconsin classified any observation of carbon dioxide concentration above the draft hood of at least 1000 ppm above the level measured prior to burner operation as a spillage event, and found that spillage occurred in more than $40 \%$ of all burner firing events. Even the least-spillage-prone units showed spillage in about $24 \%$ of firing events. Of several thousand firing events, hundreds of cases were found in which spillage lasted more than $1 \mathrm{~min}$, but only 6 were identified in which spillage lasted more than 5 min (Pigg 2010). The time from ignition to full vent flow (the end of all spillage) appeared in this study to be a characteristic of individual systems, with some routinely spilling longer than others.

Koontz (2002) summarized several field studies of appliance venting performance from the results of the CVEP as applied to about 115 homes located in Toronto, Minneapolis-St. Paul, Omaha, and Washington, D.C. (see Table 9).

Table 9. Results of CVEP Applied to Atmospheric Draft Appliances

\begin{tabular}{|c|c|c|c|c|c|}
\hline Location & $\begin{array}{c}\text { Appliance } \\
\text { Type }\end{array}$ & $\begin{array}{l}\text { Number } \\
\text { of Cases }\end{array}$ & $\begin{array}{c}\text { Minimum Zone } \\
\text { Depressurization } \\
\text { at Which Flow } \\
\text { Developed } \\
\text { (Pa) }\end{array}$ & $\begin{array}{c}\text { Mean Zone } \\
\text { Depressurization } \\
\text { at Which Flow } \\
\text { Developed } \\
\text { (Pa) }\end{array}$ & $\begin{array}{c}\text { Maximum Zone } \\
\text { Depressurization } \\
\text { at Which Flow } \\
\text { Developed } \\
\text { (Pa) }\end{array}$ \\
\hline $\begin{array}{c}\text { Omaha and } \\
\text { Washington, D.C. }\end{array}$ & Furnace & 31 & 1.9 & 7.1 & 16.3 \\
\hline $\begin{array}{c}\text { Minneapolis- } \\
\text { St. Paul }\end{array}$ & Furnace & 15 & 3.0 & 6.8 & 10.8 \\
\hline Toronto & Furnace & 40 & 2.7 & 6.2 & 10.7 \\
\hline $\begin{array}{c}\text { Omaha and } \\
\text { Washington, D.C. }\end{array}$ & $\begin{array}{l}\text { Water } \\
\text { heater }\end{array}$ & 56 & 1.4 & 6.8 & 15.6 \\
\hline $\begin{array}{l}\text { Minneapolis- } \\
\text { St. Paul }\end{array}$ & $\begin{array}{l}\text { Water } \\
\text { heater }\end{array}$ & 30 & 2.3 & 6.1 & 13.5 \\
\hline Toronto & $\begin{array}{l}\text { Water } \\
\text { heater }\end{array}$ & 40 & 4.1 & 9.7 & 32.0 \\
\hline
\end{tabular}

The results show striking variability in the combustion zone depressurization level that can be overcome by natural draft appliances. The range between the minimum and maximum pressure measured in each geographic location is particularly wide. The smallest minimum-to-maximum range (in Minneapolis-St. Paul) is $7.8 \mathrm{~Pa}$.

The wide range of results from CVEP testing indicates that a single depressurization limit as a test of combustion safety is a very crude instrument-any particular limit selected is almost certain to lead to many false positives (if set low) or false negatives (if set high). 
This study also compared short-term (on-site) testing for backdrafting to monitored results from the same homes. The short-term backdraft tests were apparently performed under WCD conditions, and spillage that continued beyond $5 \mathrm{~min}$ was classified as a failure. Monitoring was performed for periods of about 1 week in each home, and was repeated in summer or fall and again during winter in each home. Observation of positive pressure in the vent system for more than about $90 \mathrm{~s}$ /day during appliance operation was considered evidence of spillage under natural operating conditions. The authors recognize that this test may identify spillage in homes that exhibit transient spillage only during a brief period when appliances first fire; we concur with this observation.

The results show that using short-term spillage tests to predict backdrafting under natural operation is problematic, resulting in a large number of false positives $(22 \%$ of all the furnace and water heater tests performed across all communities). These false positives imply that the WCD test is at least somewhat conservative; failure to vent properly when several exhaust appliances are operating does not mean this condition will occur during normal operation, as observed over a couple of weeks. False negatives were also reported in a number of cases. This result is unsurprising, however, given the liberal definition of spillage under normal operating conditions.

Bohac (2002) reported on tests in homes involved in an airport noise-abatement retrofit effort in Minnesota. Tests included WCD and spillage testing under WCD and natural conditions (defined here as continued operation of the appliance with no intentional depressurization, rather than a cold start of the appliance). The vent size for the combined vent (the vent or chimney liner serving both water heater and furnace/boiler) was compared to the size required by the NFGC. (See Table 10 for results.) 
Table 10. WCD and Spillage Test Results

\begin{tabular}{|c|c|c|c|c|c|c|c|c|}
\hline & \multicolumn{4}{|c|}{ Natural Draft Water Heater } & \multicolumn{4}{|c|}{ Natural Draft Furnace } \\
\hline $\begin{array}{c}\text { Spillage Test } \\
\text { Results }\end{array}$ & 冚 & $\begin{array}{c}\text { Median Worst- } \\
\text { Case CAZ } \\
\text { Pressure } \\
\text { (Pa) }\end{array}$ & $\begin{array}{c}\text { Worst-Case } \\
\text { Pressure } \\
\text { Exceeds } \\
\text { Limit }\end{array}$ & $\begin{array}{c}\text { Average Ratio } \\
\text { of Vent Size to } \\
\text { NFGC } \\
\text { Standard }\end{array}$ & 冚 & $\begin{array}{c}\text { Median } \\
\text { Worst-Case } \\
\text { CAZ Pressure } \\
\text { (Pa) }\end{array}$ & $\begin{array}{l}\text { Worst-Case } \\
\text { Pressure } \\
\text { Exceeds } \\
\text { Limit }\end{array}$ & $\begin{array}{c}\text { Average Ratio } \\
\text { of Vent Size to } \\
\text { NFGC } \\
\text { Standard }\end{array}$ \\
\hline $\begin{array}{c}\text { Pass } \\
\text { (Worst-Case) } \\
\text { Pass } \\
\text { (Normal } \\
\text { Conditions) }\end{array}$ & $81 \%$ & -1.0 & $8 \%$ & 0.97 & $90 \%$ & -1.1 & $10 \%$ & 0.91 \\
\hline $\begin{array}{c}\text { Fail } \\
\text { (Worst-Case) } \\
\text { Pass } \\
\text { (Normal } \\
\text { Conditions) }\end{array}$ & $9 \%$ & -3.5 & $51 \%$ & 0.96 & $6 \%$ & -3.3 & $50 \%$ & 0.86 \\
\hline $\begin{array}{c}\text { Fail } \\
\text { (Worst-Case) } \\
\text { Fail } \\
\text { (Normal } \\
\text { Conditions) }\end{array}$ & $11 \%$ & -1.1 & $9 \%$ & 0.79 & $4 \%$ & -1.2 & $5 \%$ & 0.65 \\
\hline
\end{tabular}


Some interesting observations can be made based on these results:

- The very large fraction of homes in which the appliances passed the spillage test under depressurized and natural draft conditions (81\% of water heaters and $90 \%$ of furnaces) were characterized by low average levels of depressurization and by adequate relative vent size.

- The homes that failed under WCD, but passed under natural pressure conditions, were characterized by more severe depressurization $(-3.5$ and -3.3 Pa median values for water heaters and furnaces, respectively). This is consistent with the simple theory that greater depressurization will increase the likelihood of spillage. These homes had relative vent sizes similar on average to the first group.

- In the most striking result, homes that failed the natural draft test had much smaller average relative vent sizing than the other groups; average ratios to NFGC requirements were 0.79 for water heaters and 0.65 for furnaces.

This final observation implies that proper vent system sizing may be a very strong indicator of venting performance for combustion appliances under normal operating conditions.

The lack of consistent guidance on how to define acceptable levels of vent spillage is highlighted in a literature review of 50 documents related to depressurization, backdrafting, and spillage from vented gas appliances published by the Gas Research Institute (GRI 1995). It concluded "that the phenomenon of depressurization-induced spillage is not well understood despite the fact that considerable research has been conducted on the subject." A conclusion drawn from this literature review states: "the study suggests that problems associated with depressurization induced spillage are quite rare yet at first glance some studies indicate that backdrafting can occur in a large number of existing homes with gas furnaces and water heaters. Based on the literature, the question that cannot be answered with a great degree of confidence is, "What precisely is the extent of the problem?"

One additional issue regarding combustion safety testing in the context of energy efficiency programs is disagreement over the role of energy auditors in performing such tests. Some have argued that such testing should be done only by HVAC professionals who are trained and equipped for the task (Sterner 2010).

In summary, we believe the efficacy of current combustion safety testing procedures must be questioned on the following grounds:

- There appears to be a poor correlation between failure in one-time combustion safety tests and spillage during normal operation.

- Many, and probably most, atmospherically vented appliances frequently spill for up to a minute or somewhat longer on startup. Prolonged spillage appears to be rare. Tests that fail an appliance on any spillage longer than $60 \mathrm{~s}$ may be unduly conservative.

- Cold vent establishment testing shows an extremely wide range of depressurization levels under which a positive draft may develop in individual appliances. Zone depressurization limits are likely a poor test of proper vent performance. 
- Vent sizing compared to NFGC standards may be an important indicator of proper vent performance and should be considered in combustion safety evaluation.

- There is a lack of agreement about the level of training that should be required for technicians performing combustion safety tests.

\subsection{Radon}

Several technologies are available for measuring radon concentrations in indoor air. Radon carries health risks that are thought to be related to long-term average exposure, and all common measurement methods provide average or integrated concentration over some specific time interval. (Continuous monitors can provide measurements over periods as short as an hour or so, as well as averages over longer measurement periods.) The EPA classifies radon tests performed for 2-90 days as short-term, and tests performed for longer periods as long-term. Radon comes into homes with gas from the soil and concentrations are generally higher in basements than above-grade spaces. The EPA recommends testing in the lowest level of a home that is finished or is likely to be occupied (EPA 2009).

In practice, short-term radon tests are almost always performed over 2-7 days. This short test period allows radon tests to be performed in the context of real estate transactions where delays of longer than a few days would be impractical.

Among the most commonly used radon measurement technologies are charcoal absorption canisters that are used for 2-7 days (short-term), and alpha track detectors, generally deployed for periods of 3-12 months (long-term). Both are one-time tests in which the measurement device is destroyed in analysis. Many commercial radon test organizations purchase reusable detectors that reduce operating costs over time, the most common of which are probably electret detectors and continuous radon monitors. Both technologies can be used for short- or long-term tests. (See Appendix B for a more complete description of radon measurement technologies.)

EPA recommends taking measures to reduce radon levels in homes with average concentrations of $4 \mathrm{pCi} / \mathrm{L}$ (picocuries per liter of air) or higher (EPA 2009). EPA suggests starting with a shortterm test and, if the results show a concentration of $4 \mathrm{pCi} / \mathrm{L}$ or higher, following up with either a second short-term test, or a long-term test, and implementing radon reduction measures if results (the average of short-term tests, or a single long-term result) show levels of $4 \mathrm{pCi} / \mathrm{L}$ or higher. ${ }^{8}$

\subsubsection{Evaluation of Radon Test Methods}

Radon testing as currently practiced has several shortcomings: variability of radon levels over time, variability in the equilibrium factor, and the disconnect between measured values and occupant exposure. We discuss each of these in turn.

\subsubsection{Variability of Radon Concentrations}

The variability of measured radon concentrations in buildings has been the subject of several studies. A Minnesota study of 62 homes yielded a coefficient of variation (COV) of $70 \%$ for four-day measurements under closed-house conditions compared to an annual average values,

\footnotetext{
${ }^{8}$ EPA suggests considering repeat testing even when initial testing shows levels below 4 pCi/L (EPA 2009).
} 
with an efficiency rate (fraction of homes properly classified as above or below $4 \mathrm{pCi} / \mathrm{L}$ ) of 0.77 . (This value can be compared to an expected efficiency of 0.5 using a random classification such as a coin toss.) This report concludes "radon measurements that only average the concentration for a few days do not provide an accurate estimate of the annual average radon concentration nor a sound basis for mitigation decisions in houses in central North America" (Steck 2004).

An earlier EPA study of 20 homes in Montana shows strong seasonal trends in the radon levels averaged across 20 homes (interesting in part because other studies show that radon levels between homes in a geographic region do not necessarily follow uniform seasonal trends). The results are not presented in terms of a COV, but show a ratio of maximum to minimum monthly average concentration of greater than 3 (EPA 1986).

Even a year-long measurement cannot be taken as completely representative of long-term concentrations. A study of 196 homes in Iowa found a median COV of annual concentration from one year to the next of $12 \%$, which increased to $19 \%$ when the first year value was compared to a third year in a subset of these homes subject to further testing. The authors suggest a COV of about $7 \%$ can be attributed to basic measurement variability, with the remainder due to true changes in radon level year-to-year (Zhang 2007).

A larger study that included about 1,700 year-long measurements over periods of 4-19 years in 98 Minnesota homes yielded a median COV of $26 \%$ for repeated annual measurements in individual homes (Steck 2009).

The EPA recognizes the issue of variability in radon measurement in A Citizen's Guide to Radon: "Sometimes short-term tests are less definitive about whether or not your home is above $4 \mathrm{pCi} / \mathrm{L}$. This can happen when your results are close to $4 \mathrm{pCi} / \mathrm{L}$. For example, if the average of your two short-term test results is $4.1 \mathrm{pCi} / \mathrm{L}$, there is about a $50 \%$ chance that your year-round average is somewhat below $4 \mathrm{pCi} / \mathrm{L}$. However, EPA believes that any radon exposure carries some risk - no level of radon is safe. Even radon levels below $4 \mathrm{pCi} / \mathrm{L}$ pose some risk, and you can reduce your risk of lung cancer by lowering your radon level" (EPA 2009).

\subsubsection{Equilibrium Factor}

The equilibrium factor in radon measurement is related to the different behavior of radon gas compared to the ions formed by the decay of radon. Radon atoms that enter a building are generally electrically neutral, and tend to remain airborne and unattached to particulate matter. Similar to nitrogen gas, radon is not likely to adhere to lung tissues when inhaled, and does not contribute greatly to the radiation doses that lead to lung cancer. Radon decay products, however, carry electrical charges immediately after their formation, and tend to adhere to solid surfaces and airborne particulates. These decay products, when inhaled, are much more likely than radon gas to remain in the lungs, and are responsible for most of the radiation exposure of lung tissue.

The rate at which the decay products are removed from the air depends on many factors, including the amount of particulate present, air circulation, and air filtration. The equilibrium factor ("F") refers to the ratio of the decay energy available from radon decay products under actual conditions to the decay energy available if they were to remain entirely airborne. The 
highest value possible is 1.0 , and EPA uses a generalized estimate of 0.5 to estimate radon risks (Lewis 2009).

The common measurement methods respond to radon gas concentration; thus, although human dosage is heavily dependent the equilibrium factor, variations in the effective equilibrium factor are important. And the value does apparently vary across buildings: one report of work done in India reports equilibrium factors of 0.02-0.90 across 150 homes (Ramola 2003).

\subsubsection{Occupant Exposure}

Finally, patterns of occupant exposure to elevated levels of radon and daughter species is a critical factor. The risk of developing lung cancer is thought to be related to total integrated exposure over time. Clearly, the risk is heavily influenced by the amount of time an individual spends in a high-radon environment. For example, a person spending 14 hours per day in a home with a "safe" level of $3.9 \mathrm{pCi} / \mathrm{L}$ may be at greater risk than someone who works in a basement with $80 \mathrm{pCi} / \mathrm{L}$, but for only 4 hours per week. EPA recommends testing for radon on the lowest occupied level of a home, but beyond this single suggestion, radon testing protocols do not address occupant exposure (EPA 2009).

\subsection{Moisture}

Because of the direct association between mold growth, fungal decay, and dust mite proliferation with high moisture levels, inspecting for water leakage or moisture accumulation has become part of many energy audit and building inspection protocols. Sources of excess moisture can include:

- Internal leakage (e.g., plumbing, leaky aquarium)

- External liquid water leaking into building or building envelope

- Interior high humidity and subsequent condensation.

Every home and building exists in a state of dynamic equilibrium with the surrounding environment. Moisture plays an important role in durability and indoor air quality. Uptake and discharge of water (whether gas, liquid, or solid) varies in response to outdoor weather and climate. Indoor environmental conditions also create a sort of weather and climate. Moisture flux can have short- and long-term effects on building materials, finishes, and occupants. Modifying structures to promote energy efficiency can significantly alter moisture balance. To prevent harmful outcomes, efforts should be made to anticipate the consequences of alterations before the work begins.

Liquid water that enters wall systems can be removed by draining (using drainage plane and rainscreen constructions), or it can be turned into vapor and ventilated out. Reducing air leakage and decreasing heat transfer through the building envelope are common features of an energyconserving retrofit. An unintended consequence, particularly in heating climates, may be a loss of drying potential in the building envelope. Water has a high specific heat and requires a good deal of energy to turn from liquid to gas. In its original configuration, energy loss through the envelope provided a benefit in an increase in drying potential. Reducing heat transfer and air 
leakage can alter the moisture balance of the structure, possibly to the detriment of the sheathing, siding, and framing.

An excellent illustration is the sash weight cavity that is a common feature of double hung windows in many older homes. As penetrations in the wall assembly, windows naturally leak air and water in response to weather conditions. There is a demonstrable and large energy loss through these window assemblies - cold air blows in and heat leaks out through the large hollow spaces on each side of the window. There is an energy cost in such an assembly and a hidden benefit in durability. Many such windows are in perfect condition, with little or no signs of moisture damage despite nearly 100 years of exposure to rain, wind, snow, and ice. Whether rain penetration from outside or condensation of warm interior moisture migrating into the open sash cavities, liquid water is readily vaporized and exhausted to the outside by the heat loss through the assembly. The window and its leaks are part of the home's dynamic moisture balance. Installing friction fit modern glazing and filling the sash cavities with insulation saves heating and cooling costs, but has the potential to add to the structure's moisture load, which may decrease durability.

Although the behavior of water may be predictable in simple systems and at a small scale, its behavior at the scale of whole buildings is difficult to predict. Evaluating the wetting and drying capacity of a building before working on it is a challenging task. Any single set of moisture measurements will provide information, but with little predictive value. This is similar to trying to determine long-term outdoor climactic conditions by taking one look out a window. Evaluating the dynamic moisture balance requires a thorough and cautious approach. The realities of the modern building industry dictate that time is money, and there will unlikely be sufficient time and resources to perform a thorough long-term evaluation of moisture conditions. The simplest indicators of long-term climate in a particular locale are the plants, animals, and landforms. Homes and buildings can be similarly evaluated. When properly collected, relevant observations and measurements provide at least an estimate of a structure's dynamic moisture balance, and allow an estimate of the possible hidden consequences of performing energy upgrades. A proper moisture evaluation before an energy upgrade is performed is necessary to avoid increasing the indoor moisture load while insulating and air sealing.

\subsubsection{Moisture Test Protocols}

Moisture inspection procedures included in energy audits tend to be nonquantitative and fairly subjective. Even more thorough guides to home inspection often lack specific detail when addressing moisture. The Housing and Urban Development Residential Rehabilitation Inspection Guide, for example, is more than 100 pages long and includes many recommendations for identifying moisture issues (e.g., checking sump pump for proper discharge and clothes washer connections for leakage), but no quantitative tests are discussed (HUD 2000). Similarly, a wellwritten guide to moisture problems in manufactured housing published in 2000 has no quantitative measurement recommendations beyond suggestions for indoor relative humidity levels (MHRA 2000).

Some procedures call for generalized quantitative observations of the area affected by moisture. For example, a pilot checklist developed by the CDC calls for characterizing the surface area 
affected by staining, dampness, and visible mold, and for judging the density of visible mold, in one of four categories (CDC 2011).

The moisture/mold assessment procedures listed in "Healthy Indoor Environment Protocols for Home Energy Upgrades (EPA 2011a) cover a basic visual investigation of the property before work is initiated. Several handheld instruments can reveal moisture issues that are not visible to the naked eye. They can add another dimension to moisture detection, but provide only a snapshot over a very short time frame. That which was damp in the past, may be dry during the observation period. Any user needs training on these instruments in addition to time in the field.

The following instruments can generate useful information. Their use should be part of a thorough moisture audit before an energy-related retrofit is performed.

\subsubsection{Pin Moisture Meter}

The most challenging mold and moisture problems lurk behind or beneath finished surfaces. Moisture meters can help the inspector to locate hidden dampness. The moisture meter pins are inserted into the surface of interest. When the meter is triggered, the indicator needle swings to the right in response to moisture. If the surface is saturated, the needle will swing across the dial and contact the right side with an audible click. As the meter is designed for measuring the moisture content of wood, the maximum reading is $30 \%$, the saturation point. Although the moisture content reading will not be accurate, the meter can be used to find damp spots in materials such as drywall. If the destructive effects of making a large number of holes is acceptable, plumes of dampness can be identified by comparing readings from several locations.

The instrument comes equipped with pins about $1 / 2$ in. long, but longer pins can be used as well. The shafts of the longer pins must be insulated so only the tip collects moisture readings.

Novices can familiarize themselves with the instrument's performance by measuring intentionally wetted pieces of sample material. With repeated use, the pin meter provides an added benefit. Fresh, unwetted material provides a certain resistance when the pins are pushed in. Repeatedly wetted material is much more easily penetrated.

\subsubsection{Nonpenetrating Moisture Meter}

The nonpenetrating meter can detect moisture up to $2 \mathrm{in}$. below the surface on which it rests. The meter has three sensitivity settings. On the appropriate setting it is possible to find a leaking water supply behind a ceramic tile shower wall. The instrument's sensitivity makes it less useful in very humid environments, where the thin veneer of bound surface water gives false positive readings. Some surfaces, such as vinyl wall coverings, are opaque to the detector. Errors are also possible because metal sets off the meter. Moisture tends to show a concentration gradient, with the indicator needle moving from low to high as the meter approaches the wettest area. Metal makes the indicator jump instantly from zero to the maximum. As with the pin meter, training requires the instrument be used on samples with known moisture levels.

The surface meter can be quickly used to assay walls, floors, and ceilings of almost any material, including wood, plaster, and drywall. It can also be used on concrete surfaces, such as slabs and foundation walls, but readings may be less reliable. Particular focus should be on edges of wall 
assemblies and around and below windows. It is important to remember that these meters give no indication about whether a wall was previously wet but is now dry.

\subsubsection{Infrared Camera}

Infrared (IR) cameras produce images that sense temperature differences. Warm appears white and cold is dark. The camera is not a moisture detector, but evaporative cooling often makes IR images of damp areas appear darker than adjoining dry portions. Use of this technology requires good training before IR scanning can be used as a reliable moisture diagnostic tool. The IR camera works when there is a temperature difference between the two sides of the assembly. The camera highlights thermal bridges inside the wall assembly such as studs in insulated walls. Any voids in an insulated wall are delineated as dark or light areas, depending on the direction of heat flow toward or away from the side viewed by the camera.

IR cameras cost $\$ 1500-\$ 100,000$. The higher priced cameras are much more sensitive and can discern a wider range of temperature differences in a single image.

\subsubsection{Temperature, Relative Humidity, Dew Point Thermometer}

There are a variety of thermometers on the market. Reliable instruments that also report dew point are more expensive. Some meters have a long needle probe that can measure wall cavity humidity and temperature. Small holes, less than $1 / 2$ in. in diameter, are drilled into the wall of interest, then sealed over with tape. A conical rubber sleeve is fitted on the probe, which is then inserted into the holes. The rubber sleeve seals the hole, allowing the moisture level in the cavity to be accurately determined.

\subsection{Mold Sampling}

Although inspection for and correction of moisture accumulation is widely accepted, most sources do not recommend performing sampling specifically for molds except in special circumstances. The American Industrial Hygiene Association suggests that mold sampling may be useful under certain circumstances, for example when airborne mold is suspected but cannot be visually located, or to help resolve specific health or legal issues, but states that:

If samples are collected, regardless of the purpose, the results should help answer a clear question. Sampling without a specific purpose greatly increases the chances of generating useless data (AIHA 2001).

CDC does not recommend routine sampling for molds.

Generally, it is not necessary to identify the species of mold growing in a building. Measurements of mold in air are not reliable or representative. If mold is seen or smelled, there is a potential health risk; therefore, no matter what type of mold is present, you should arrange for its removal. Furthermore, sampling for mold can be expensive, and standards for judging what is and what is not an acceptable or tolerable quantity of mold have not been established (CDC 2011). 
A New York City guideline states "Environmental sampling is not usually necessary to proceed with remediation of visually identified mold growth or water-damaged materials" (NYCDHMH 2008).

A number of methods are used for sampling (EMSL 2010) and analysis of molds:

- Air filtration sampling. Air is drawn through a filter and the material deposited is identified microscopically. This method allows the user to quantify spore concentrations in air, but generally does not allow molds to be identified to the species (or sometimes even genus) level, or determine the viability of spores.

- Culturable air sampling. Air is drawn over a medium that supports fungal or bacterial growth. The medium is inspected after several days. Samples to be cultured typically require special handling (fast delivery and kept cool during shipment). This method allows identification of individual species.

- Surface sampling. Surface sampling uses tape or swabs to collect particles from a surface. These are inspected microscopically to identify mold growth (but not speciation or viability). Spores collected by sterile swabs may be cultured to allow for species identification.

- Bulk sampling. Bulk sampling refers to collection of a piece of the material on which mold growth is suspected; e.g., removal of a piece of drywall. Bulk samples may be inspected microscopically, or cultured.

There seems to be universal agreement that the fundamental solution to problems with mold growth in buildings is to correct or remove the sources of excess moisture. EPA's Web site states: "If there is mold growth in your home, you must clean up the mold and fix the water problem. If you clean up the mold, but don't fix the water problem, then, most likely, the mold problem will come back" (EPA website).

Many resources on remediation of mold problems also call for removal of molds. The EPA website, for example, calls for cleaning mold from hard surfaces, with the note that "absorbent materials such as ceiling tiles, that are moldy, may need to be replaced" (EPA 2012).

The New York City guidelines includes more detail on cleanup procedures, with recommendations covering cleaning methods and the use of personal protective gear as a function of the area of mold growth (NYCDHMH 2008).

Sequestered moisture can lead to mold problems that produce no discernible odors or visual cues. In such cases, thorough testing can help detect the problem. Examination of multiple air and settled dust samples collected across a building may reveal a concentration gradient that points to a hidden reservoir. This is particularly true with damp carpeted slabs and lower parts of wall assemblies in finished below-grade spaces.

The problem with sampling is that to generate proper evidence, the investigator should collect and analyze the samples - perhaps 10-20 to produce a complete picture. Sending this many samples to an independent laboratory for analysis is expensive, and prevents the investigator 
from examining the results firsthand, which is often much more meaningful than reading a laboratory report.

A particularly useful sampling method is the tape lift. Common translucent office tape is pressed down on the surface of interest. The tape is then applied to a glass microscope slide, which is then immersed for several hours in a staining jar filled with acetone. The acetone dissolves the backing material and leaves the optically transparent adhesive surface, with its particle load, still adhered to the slide. A cover slip is then fastened to the slide with transparent mounting medium such as Shur-Mount. After an hour of drying time, the slide is ready for viewing. If properly stored, the prepared tape lift slide can be kept as a permanent record.

\subsection{Lead}

Onsite lead test kits are readily available that the homeowner can use to determine if lead is present in the home. EPA provides a list of providers whose kits have passed tests that indicate a specific level of reliability (EPA 2011e).

In addition to active testing, EPA advises homeowners and workers to assume that homes built before 1978 may have lead-based paint, and to comply with the provisions of the Renovation, Repair and Painting (RRP) Program Rule.

The RRP Program Rule: 40 CFR Part 745 establishes regulations for lead-safe construction practices. This rule took effect in April 2010 and requires any person conducting regulated renovation activities to be trained, certified, and compliant with work practice, cleaning, and recordkeeping requirements. Regulated renovation activities include work scopes that will disturb more than $20 \mathrm{ft}^{2}$ of exterior lead painted surface area and $6 \mathrm{ft}^{2}$ of any interior surface.

The EPA has authorized states, tribes, and territories to administer their own RRP program that would operate in lieu of the EPA regulations. Currently Alabama, Georgia, Iowa, Kansas, Massachusetts, Mississippi, North Carolina, Oregon, Rhode Island, Utah, Washington, and Wisconsin have been authorized by EPA to operate their own programs.

\subsection{Asbestos}

Laboratory testing of materials suspected of containing asbestos is the only way to identify if asbestos is present. Many programs, however, rely on the energy auditor to make a visual assessment, and to avoid disturbing the material if they suspect it to contain asbestos (EPA 2010a, 2010b).

OSHA initiated regulations in the early 1980s to address asbestos exposure during construction and demolition processes; revisions were made in 1986 and 1988. The EPA in 1989 banned all new uses for asbestos (DOL 1986).

\subsection{Legionella}

Legionella bacteria can be identified in culture tests using samples from suspect water systems such as domestic hot water, humidifiers, and pools. These tests, however, are complicated by the requirement that the sample be kept cool in shipment and be delivered to the analysis laboratory within $24 \mathrm{~h}$ (EMSL 2010). 


\subsection{Particulates}

When interior building surfaces and assemblies are disturbed during energy-related retrofit projects, clouds of irritating — and perhaps toxic — particles may be released. Large particles fall at the same rate, in response to gravity. Microscopic particles, those below $(10 \mu$ in aerodynamic diameter) have their falling rate retarded by the fluid viscosity of the air. A 3- $\mu$ mold spore has a falling velocity of about a $3 \mathrm{ft} / \mathrm{h}$ in still air.

Tiny particles can remain suspended for hours, and travel good distances from their points of origin. Once they become airborne, microscopic particles such as asbestos fibers, lead paint fragments, and fungal debris can disperse throughout a home or building, eventually landing and becoming components of the settled dust.

Destructive processes such as drilling, sanding, and cutting are common sources of constructionrelated dust. Several methods are used to contain and capture particulate pollution. The first is to capture exhaust power tools with high-efficiency particulate air (HEPA) filtration. These tools are commonly used in lead abatement projects. It is critical that the vacuum orifice be as close as possible to the source. It is simple to direct positive pressure, but impossible to direct negative pressure. It is also important that the HEPA filter actually perform as it is designed. Filters can be poorly installed, with bypasses, or become clogged and ineffective if overloaded.

Even the best tools cannot capture all generated dust. The work area must therefore be contained with effective barriers so work-related dust can be contained.

The most commonly used barriers are made from plastic sheeting and tape. HEPA filtered exhaust air scrubbers allow the entire work area to be under negative pressure; the only outlet for airflow is through the air scrubber. A digital pressure gauge can be used to monitor the pressure, and workers need to be trained to observe the inward pointing belly on the plastic sheeting that gives an instant indication of the pressure regime. Access to the work area should be through an air lock made from two Zip-doors. Proper use of the air lock, with only one door open at a time, prevents a loss of containment during entry and egress from the work area.

Work-generated dust can be further contained through proper job-site sanitation. Sticky track pads should be used to remove dirt from shoes when leaving the work area. Once the work is completed, the area must be carefully HEPA vacuumed and damp cleaned before the containment is taken down.

Another valuable piece of monitoring equipment is the airborne particle counter. These instruments vary in price and quality. The better ones cost at least $\$ 5000$, and count particles of $0.1-25 \mu$. They can be used to monitor the air quality outside the work area to look for particle bursts that indicate the containment has been compromised. A good particle counter can also be used to test the HEPA device to see whether it is actually capturing tiny particulates.

\subsection{Other}

A wide variety of other test methods may be employed in specific cases, for example, when occupants come forward with a complaint about indoor air quality. 
Problem-solving investigations differ from the general IEQ and durability testing that is the primary topic of this report. Investigations triggered by a specific complaint or problem will often go into much more depth and use testing methods beyond those employed in general testing. They may also ignore some elements of a general testing protocol, for example, addressing an odor complaint may not include combustion safety testing.

ASTM offers one approach to organizing investigations of indoor air quality problems identified by homeowners or occupants. This suggested approach includes information gathering, development of hypotheses, testing of hypotheses, identification of causes, and proposed solutions. Three phases of information gathering are suggested (if required): initial interview and walk-through, detailed assessment of building and systems, and quantitative measurements. It is implicit that the assessments and measurements performed are to be tailored to the complaint and likely causes, and as such, the standard does not call for any specific tests to be performed in all cases (ASTM, 2006).

Jeffrey May's book My House is Killing Me is replete with information and suggests many clues that may be helpful in identifying sources of irritants and pollutants in homes (May 2001). 


\section{Testing Alternatives}

\subsection{Combustion Safety Evaluation}

Combustion safety evaluations may be enhanced by including an inspection of venting systems, and screening to determine compliance with NFGC or other standards. Issues associated with oversized chimneys have long been recognized, and as mentioned earlier, undersizing of vent systems may be a significant predictor of spillage or poor performance.

Combustion safety evaluation might be expanded to include checking for the presence of oxygen depletion sensors (ODSs) in gas combustion appliances. ODSs are pilot light systems designed to prevent main burner ignition when oxygen levels in the combustion supply air drop significantly. Reduced oxygen increases the likelihood that $\mathrm{CO}$ will be produced as a combustion product. ODSs have been required on unvented space heaters since 1980, and the industry has claimed that there have been no CO deaths from the use of any unvented heater equipped with an ODS (Bodzin 1998). Verifying the presence of an ODS, in particular when inspecting unvented combustion appliances manufactured before 1980, might carry safety benefits.

\subsection{Fuel Gas Leakage}

As mentioned earlier, test protocols addressing fuel gas leakage generally call simply for the repair of any leak with no differentiation between minor and severe leaks. Some guidance for defining severe or immediately hazardous leaks may be useful. In the Pocket Guide to Chemical Hazards, the National Insitute for Occupational Safety and Health states that the concentrations of chemicals considered "immediately dangerous to life and health" is set at $10 \%$ of the lower explosive limit for flammable materials, "for safety considerations even though the relevant toxicological data indicated that irreversible health effects or impairment of escape existed only at higher concentrations." This appears to suggest a concentration measurement as a fraction of explosive limit as a possible threshold test for leaking fuel gas. Methods for making such measurements are not discussed, however, and would need to be developed for this type of test to be useful (CDC 2010).

\subsection{General Fire Safety}

Thousands of fires, associated with hundreds of deaths and hundreds of millions of dollars in property damage, are caused each year by home cooking and combustion appliances. To the extent that energy auditing and energy programs include inspection, testing, or advice about these appliances, including fire safety information as part of testing and auditing protocols is logical. Examples would include specific inspection procedures for flammable materials in areas near combustion appliances, while recognizing the reduced risks from safe designs such as flammable vapor ignition resistant water heaters, and inspection of dryer vents for lint buildup.

\subsection{Plumbing Leaks}

Small plumbing leaks can lead to significant damage (mold growth, structural decay).

Observation of water consumption over a period when no use is expected may help to screen for leaks that have not otherwise been identified. This might be done by engaged homeowners who are willing to photograph or otherwise record the position of their water meter at the beginning and end of a period away from home (a workday or vacation). Automatic water consumption by icemakers, humidifiers, water softeners, etc. would render this method impractical. 
Inspection of washing machine hoses (a cause of significant water damage when they burst) might be added to audit procedures. Specific inspection or test methods would need to be developed.

\subsection{Radon}

Measurement variability means that reliance on short-term tests yields many false positives and false negatives (compared to the accepted action level of $4 \mathrm{pCi} / \mathrm{L}$ ). A single long-term test would reduce the variability of results significantly. In very high radon areas, where exposures may be high, this might be replaced with a pair of short-term tests. If radon levels appear high in an initial short-term test performed with an activated charcoal canister, use of an alpha track detector for follow-up testing can provide a somewhat longer test period and a compromise between the desire for quick results and reduced variance.

\subsubsection{Radon on Glass-Retrospective Estimates}

Observation of the historical radon levels in a home over a period of many years may be possible using a phenomenon involving glass surfaces. One step in the decay chain of radon is the transition from polonium 214 to lead 210. This decay imparts kinetic energy sufficient to embed the lead atoms in nearby glass surfaces. Lead 210 decays in turn to bismuth 210, polonium 210, and finally to lead 206 (which is stable). The half-life of lead 210 is 22.3 years, which means the concentration of this isotope in a glass surface provides some indication of historical exposure to radon decay products over a period of years. The concentration of lead 210 in a glass surface can be measured via the decay of polonium 210 to lead 206, which produces an easily observed alpha particle.

Several researchers have worked on practical methods for using this principle in retrospective radon concentration analysis. In one case, Daniel Steck of Saint John's University, in Collegeville, Minnesota) developed and uses the "RRD detector", which includes three measurement surfaces. Two face the glass, and use different "filter" materials that exclude background decays (which are inherent to the glass, not associated with radon exposure). The third surface records decays from currently airborne radon.

Steck (1999) reports the correlation of glass measurements with repeated 1-yr alpha track canister measurements from two studies (Minnesota and Iowa). The correlation coefficient from the Minnesota study was 0.8 , and from the Iowa study was 0.5 . The slope of the relationship between glass measurement and alpha track measurement was substantially different from the two studies. Possible reasons for variation between the decay rates observed on glass surfaces and repeated measurements made over time using other technologies include the confounding effects of other sources of radioactivity in glass, and the different effects of aerosol particulate on the test methods used.

The results appear to indicate some promise for the method, but further refinement and validation would likely be needed before it would be acceptable for widespread use beyond the research community (Brennan 2011; Steck 2011). 


\section{A General Approach}

A reliance entirely on contractor testing to ensure healthy IEQ and building durability in retrofitting will sometimes, and perhaps often, fail, because:

- Standard test protocols will never uncover all risks or problems. Most test procedures are not absolutely precise and their results have associated inherent errors. Some procedures have well-established shortcomings.

Test procedures are subject to errors because of improperly calibrated instruments, unusual conditions during testing, and other factors. Some appliances or building systems will fall outside the scope of applicability for normal test procedures and some problems may be hidden and not discovered by normal testing. Finally, auditors and technicians may make errors that lead to missed problems or misleading results.

- Identifying a hazard is not the same as establishing the associated risk. The risks associated with $\mathrm{CO}$, radon, and other contaminants are directly related to exposure. Occupant habits and lifestyles may be dominant factors in overall exposure to contaminants in the home.

- New problems may occur at any time after retrofitting. A fundamental shortcoming in relying on testing during the retrofit process is that conditions may change after work is complete. A birds' nest may fall down a chimney, creating a combustion safety problem, or a roof leak may develop and lead to a moisture problem.

- Much work is done outside the scope of programs, with no testing. Perhaps most important, a very large fraction of home retrofitting is done outside the boundaries of organized energy and weatherization programs. Most of this work is done without the benefit of organized testing for IEQ and durability issues.

\subsection{A Robust Approach}

We recommend seeking a much more robust approach that recognizes the following practical realities:

- The issues that contractors can discover via explicit testing are limited.

- Risks associated with exposure to many known or suspected hazards are impossible to quantify, and it may be impossible to attain zero risk.

- Much (if not most) residential remodeling and retrofitting is performed without including any IEQ or durability-related testing. Any mechanism that increase awareness, communication, testing, and problem resolution would help reduce problems. Recognize the hesitation of contractors outside program requirements to adopt extensive or expensive testing.

- The scope of hazards addressed by standard testing is limited. Occupants may have special sensitivities that are not normally considered. 
- The components of homes, occupant factors, and weather are interactive. Work on one system in a home may affect the performance of other systems. Holding a contractor responsible for his area of direct work is insufficient to avoid problems.

- $\quad$ Testing to be performed may depend on scope of work and reason for work

- For example, replacing one window will not likely trigger a combustion safety issue, but a complete window and siding replacement may tighten the home enough to trigger such an issue.

○ Work done to solve a particular problem such as moisture or odor may call for specialized testing.

The use of pass-fail testing (for combustion appliances, radon, and in other areas) obscures the reality of statistical distributions, variable performance, and human exposure.

\subsection{Outline of a Comprehensive Approach to Indoor Environmental Quality and Durability in Retrofitting}

We believe a multifaceted approach is required to minimize IEQ and durability hazards in homes undergoing energy and nonenergy retrofitting. Such an approach may include a number of the following elements.

\subsubsection{Contractor Education}

That a contractor's understanding of building science is an important part of identifying and reducing hazards in homes is self-evident. There are many opportunities for contractors to receive education, including activities offered by industry groups, energy programs, and utilities, as well as regional and national conferences and trade events.

Candidates for increased emphasis in educational programs include vent system inspection procedures (e.g., sizing, slopes, and installation details) for all home performance contractors, and $\mathrm{CO}$ testing procedures for HVAC contractors.

\subsubsection{Owner/Occupant Education}

Homeowners will also benefit from an understanding of building science to the extent they have the time and interest, as it should help them make informed decisions about managing risks and prepare them to identify potential hazards.

Homeowners may absorb information from any contractor, materials supplier, architect, or real estate agent, so it is important that energy program operators engage in strong trade allies outreach and education in an effort to spread knowledge as widely as possible in any community.

The focus of homeowner education might include basic information on hazards (retrofit and nonretrofit related) such as:

- Basic combustion safety

- Other CO hazards, including the extreme hazard associated with operation of enginegenerator sets and other internal combustion engines indoors

- Information on asthma and allergy triggers 
- The hazard of and testing for radon

- Fire safety, including common and appliance-related causes of fires

- The basics of moisture dynamics in homes

- Identification of mold and moisture problems

- Control of particulates, especially during construction.

Educational programs should emphasize the value of and need for maintenance of smoke alarms and $\mathrm{CO}$ alarms.

\subsubsection{Indoor Environmental Quality and Durability Standards}

Another mechanism available for minimizing hazards is to subject all homes to certain minimum standards related to durability and IEQ. Requirements covering these items might be promulgated through state or municipal codes, energy program standards, or be recommended as voluntary measures by contractors or program operators. The core list might include:

- Smoke alarms. These are already common throughout the United States, but installing alarms (including replacing battery-powered alarms with hard-wired systems) during energy retrofit work would add an element of safety to homes in which they have not been installed.

- CO alarms. CO alarms are increasingly common, but absent in many homes.

- Radon testing. Except in very low radon geographic regions, performance of a radon test might be considered a fundamental part of the ownership of any home. Long-term testing will provide more robust results, but short-term testing consistent with EPA guidelines is a reasonable starting point and is already widely accepted. Homeowners may retain the decision about what to do with the results.

\subsubsection{Design and Product Selection}

Design and product selection present an opportunity to reduce or avoid exposure to hazards before they appear in a home. Selection of solid wood cabinetry, for example, may reduce formaldehyde exposure. Selection of sealed combustion or power vented furnace and water heater may essentially eliminate the possibility of $\mathrm{CO}$ exposure from these appliances.

\subsubsection{Testing}

Many energy efficiency programs already require specific testing covering combustion safety and other items, though these procedures may be improved. Contractors not working in such programs may offer a test protocol intended to identify IEQ and durability hazards to add value to their services.

In addition to the suggestions for new or revised test procedures listed earlier, test procedures covering the following items may have value: 
- Inspection of clothes dryer vents for lint buildup (a fire hazard)

- Inspection or testing of old wiring systems for poor connections (those in which heat buildup is a fire hazard)

- A positive test for asbestos for use while onsite

- A test for radium and radon in water for use while onsite

- A functional test for smoke alarms and $\mathrm{CO}$ alarms for use while onsite (replacing batteries in any battery-powered alarm could also be a value-added safety measure that any contractor could perform)

- Inspections of chimneys, and/or routinizing recommendations for chimney cleaning where wood stoves and fireplaces are in use

- Performing a survey for combustible gas even when there is no natural gas or propane used in the home, to identify gasoline or similar volatile vapors in a combustion appliance area, or combustible gas from external sources such as landfills.

- Conducting a test to identify the garage-house connection.

\subsubsection{Identification and Notification During Course of Work}

Contractors or tradespeople who discovers apparent IEQ or durability problems in the course of their work likely discuss them with the supervisor, general contractor, or homeowner. Given that many problems are most likely to be discovered only when closed cavities are opened (e.g, during siding replacement or construction of an addition) or awkward spaces are entered (e.g., small crawlspaces), this can be a powerful method for discovering and correcting problems. The remodeling and retrofitting industry might benefit from even a modest level of formalization of the notification process. For example, contract language guaranteeing that any of a list of problem types will be reported by all subcontractors and trades to the general contractor, and in turn by the general contractor to the owner. Such a list might include:

- Evidence of infestation by insects, rodents, birds, or other animals

- Visible mold growth (perhaps specifying a minimum area)

- Rotted wood (perhaps specifying a spread over more than a specific area)

- Unsealed penetrations

- Missing insulation over more than a minimal area

- Substandard insulation

- Potentially hazardous materials such as urea formaldehyde insulation or chemicals stored in a crawlspace

- Knob and tube wiring, aluminum wiring, or any evidence of heat buildup near an electrical connection point or fixture

- Lead piping. 


\subsubsection{Informed Consent}

It is impossible to achieve zero risk in many categories of hazard associated with home retrofitting. As an alternative to the implication that all systems in a home can be considered perfectly safe, it may be reasonable to engage homeowners and occupants in discussion about their preferences for dealing with risk. Under current guidelines, for example, a measured radon level of less than $4 \mathrm{pCi} / \mathrm{L}$ is often characterized as safe. In fact, EPA documents suggest that any elevated radon level may carry some risk (EPA 2009). Similarly, radon mitigation may not be justified when the measured radon level is slightly greater than 4 in a seldom-used basement. A fully engaged homeowner can make an informed decision and consent to accept risks that others might find unacceptable.

Another application may be in the area of window and siding replacement. Much of this type of work is done without considering combustion safety, though it has the potential to increase depressurization and increase combustion product spillage. With sufficient data, a probability of creating a combustion hazard might be worked out for contractors and homeowners.

Many contractors and homeowners may find it difficult to work with this approach quantitatively. It can be very powerful, however, in that it can enable homeowners to make comparisons across categories of risk that are entirely unrelated, such as the risk of an auto accident compared to the risk associated with radon exposure.

Decision-making conflicts may arise with rental properties, where the owners pay for improvements but are not directly exposed to risks in the homes.

\subsubsection{Insurance}

Insurance enables homeowners and third parties to share risks. Insurance firms are fundamentally interested in the accurate quantification of risk, to set premiums and write policies that can cover a range of risks. As such, this industry represents a natural partner to the building science community in identifying and characterizing risks that may be covered under typical policies.

\subsubsection{Owners' Manuals}

Homeowners have many possible sources of information about home operation and maintenance. An owner's manual delivered by a contractor to a customer after retrofitting could be a trusted source of information for the homeowner and a marketing tool for the contractor.

\subsubsection{Contingent Approaches}

This concept refers to the selection of testing methods in the context of specific projects. Examples include:

- If significant airtightening is involved, combustion safety testing should be performed. The significance of airtightening might be based on the results of pre- and post-retrofit blower door testing.

- Radon testing may be recommended in many homes, but skipped in areas where radon concentrations are typically very low. 
- If work is being performed to solve a specific problem, related testing may be called for (odors, ice dams, wet basements, peeling paint, insect infestation, etc.).

\subsubsection{Corporate Engagement}

Corporations sometimes become involved in the outside lives of employees, especially when a direct or indirect benefit is involved. Corporations may offer support for educational costs, in part as a way to develop skills and increase employee value. Increasing numbers of corporations have wellness programs, which offer benefits to employees and to corporations if they lead to reduced sick days and health insurance costs.

If corporations recognize the health risks associated with hazards in the home, they may develop programs to address and reduce these hazards. A corporate-sponsored radon canister test program, for example, could be inexpensive and easy to administer. Programs offering other indoor air quality testing, or even offering professional services to evaluate IEQ issues during home improvement, might be possible for some firms. ${ }^{9}$

\subsection{Recommendations for Addressing Indoor Environmental Quality and Durability in Energy Retrofitting Projects}

This report suggests that reliance on a fixed battery of one-time testing protocols applied before or after energy retrofitting to reduce or eliminate indoor environmental hazards may have limitations. In fact, an approach that uses improved testing methods and other tools might be more effective. In addition, we believe further research is needed (see Section 8).

There is also value in establishing a set of minimum recommended IEQ and durability inspection and testing procedures for work done under Building America projects. To recommend against the use of established inspection and test procedures simply because improvements are needed would be irresponsible, and accepted procedures can fill the gap as improvements are made.

The following recommendations include limited guidance about remediation of hazards; however, the main intent is to discuss how to identify those hazards. Full disclosure of test results to the homeowner is one recommendation. The intent is that appropriate corrective measures can be pursued as needed and with the engagement of the owner. When testing is performed under certain energy programs, the program providers may require action to address deficiencies uncovered in testing, e.g. compliance with BPI requirements to specify appliance servicing where $\mathrm{CO}$ production exceeds established levels.

We do not recommend performing all applicable tests both before and after completion of retrofit work, that is, we do not recommend "test in, test out" as a blanket approach. However, we do include suggestions that tests be performed specifically either before or after retrofitting in some cases.

\subsubsection{Testing Report}

We recommend the contractor issue a testing report on each home and deliver it to the homeowner. It should include a brief description of the tests performed, the results, and an

\footnotetext{
${ }^{9}$ This element was suggested by Cindy Ojczyk of Simply Green Design.
} 
interpretation of the results of each test. The format of such a report could be largely standardized for repeated use.

\subsubsection{Gas Leakage}

We recommend reasonable diligence in identifying gas leaks in homes where natural gas or propane is used. This means maintaining awareness at all times of gas odors or odors reported by others, and testing (with a sniffer or soap bubble solution) suspected leakage areas when odors are reported. Major leaks that appear to be recent or that may have been caused by ongoing work require immediate evacuation of the home and notification to the local natural gas utility and possibly the fire department. Ongoing small leaks should be addressed in the course of work. Gas leakage should be monitored by smell by all people associated with retrofit work at all times before, during, and after retrofitting.

This recommendation is intended to apply to all contractors working in all homes, including those who do not normally carry gas "sniffers" or perform gas leak surveys. Where contractors are equipped with or are already using combustible gas detectors, we recommend they continue to do so.

\subsubsection{Combustion Safety, Vented Appliances}

Available combustion safety test methods are imperfect, but are likely to effectively detect combustion product spillage and high $\mathrm{CO}$ production in most cases. We recommend using BPI protocols as the most common standard for combustion appliance testing. This recommendation includes the following specific tests, to be performed when natural gas- or propane-fired, atmospherically vented (Category I and II) combustion appliances are present in the home. Our recommendations include some modifications in interpreting the results of these tests, as noted.

- Establish and measure worst-case CAZ depressurization (no performance limits apply under our recommendation, but recording depressurization will allow comparison of conditions when changes are made; for example, when ventilation is added).

- Measure worst-case spillage, draft, and CO (under our recommendations, no performance limits apply to draft pressures, and spillage that ends within 2 min of burner firing is considered a pass result).

- Measure spillage, draft, and CO under normal operating conditions (under our recommendations, no performance limits apply to draft pressures, and spillage that ends within 2 min of burner firing is considered a pass result).

\subsubsection{Carbon Monoxide Production, Unvented Appliances}

Measure CO production of all kitchen ovens, cooktop burners, and unvented space heaters, fireplaces, or other appliances. These tests should be consistent with RESNET protocols and in each case, the appliance burner should be allowed to operate for $5 \mathrm{~min}$ before recording the $\mathrm{CO}$ concentration (RESNET 2010). Measurements of ovens and other appliances with an exposed exhaust port should be made at the middle of the exhaust port. 


\subsubsection{Vent and Chimney Inspection of Other Appliances}

The vent and chimney of any vented solid- or liquid-fueled combustion appliance, such as a wood or pellet stove, that is not subject to the NFGC, should be professionally inspected. The inspection should include verifying the size of the vent system, the height and termination, condition of masonry and mortar throughout the system, clearances from combustibles, accumulation of soot or creosote, and blockage by any foreign material.

\subsubsection{Carbon Monoxide Alarms}

Install $\mathrm{CO}$ alarms on each level of the home, including one in each room where a vented or nonvented combustion appliance is installed. If any electrical work is performed, the electrical subcontract should include installation, if not already present, of hard-wired, battery-backup CO alarming detectors that comply with local codes (including being placed to meet local codes).

Where battery-powered smoke alarms or CO alarms are already installed, contractors should provide a written recommendation that the batteries be checked and replaced periodically, and that the alarms be replaced with hard-wired models as practical. Contractors may not want to take responsibility for replacing batteries in previously installed alarms, but might assist occupants with the task.

The $\mathrm{CO}$ sensors used in most alarms are subject to degradation over time. Maintenance or replacement should be scheduled per the manufacturer's recommendations, or at 5-year intervals if no recommendations are available. Alarms may also be replaced outright.

\subsubsection{Walk-Through Inspection for Moisture Accumulation and Mold Growth}

Severe moisture problems that are present before work begins are likely to be identified in a walk-through inspection combined with an occupant interview. We recommend performing an inspection before beginning retrofit work, and documenting any observed signs of current or previous moisture accumulation with written notes and photos. The contractor should discuss this evidence with the homeowner and identify corrective measures. As moisture problems may be seasonal and weather dependent, we do not recommend that a specific moisture inspection be performed after retrofit work.

\subsubsection{Radon}

Radon testing is problematic for energy retrofit contractors. Energy retrofitting may increase typical radon levels, primarily because overall ventilation rates may be reduced. ${ }^{10}$ Ignoring possible increased radon levels may put occupants at risk, which could be reflected in contractor liability. Testing for radon concentration, however, may carry liability for the homeowner if results must be disclosed as part of a real estate transaction. Contractors should always discuss radon measurement and the estimated costs of installing a mitigation system, and determine before proceding with work whether the following steps are acceptable:

- A pre-retrofit test is recommended only if requested by the homeowner.

- A post-retrofit test is recommended in all cases.

\footnotetext{
${ }^{10}$ Research results on this topic from the National WAP Evaluation project are expected soon.
} 
The recommended post-retrofit test procedure is deployment of a short-term charcoal canister. If the short-term measurement indicates radon concentration of $4 \mathrm{pCi} / \mathrm{L}$ or greater, we recommend a 9- to 12-month followup test using an alpha track detector. However, if the result of the first short-term test is greater than $20 \mathrm{pCi} / \mathrm{L}$, a second short-term test may be used to confirm elevated levels over a shorter time period.

Testing and mitigation require licensing in some states. Where this is true, homeowners or occupants may generally perform testing in their own homes, but contracting firms may not perform or charge for testing unless they are licensed.

\subsubsection{Lead}

All work done where lead paint is present must be done in compliance with the EPA Lead-based Paint Renovation, Repair and Painting Rule. EPA's Healthy Indoor Environment Protocols for Home Energy Upgrades summarizes the procedures needed to comply with the requirements of the rule (EPA 2011a).

\subsubsection{Asbestos}

If asbestos-containing materials (ACMs) are known or suspected, and if they are either in poor condition (fraying, crumbling, etc.) or if they must be disturbed in the course of work, their presence should be professionally confirmed before retrofit work begins. In this case, subsequent work to encapsulate or remove ACMs must be done by a licensed firm. Suspected ACMs in good condition and not disturbed in the course of work do not require further testing.

\subsubsection{Hot Water Temperature}

Although not strictly related to IEQ, high water temperature can be a safety hazard that falls under the umbrella of energy work. Our recommendations include measuring hot water temperature at the kitchen or bathroom faucet closest to the water heater. If the measured temperature is greater than $130^{\circ} \mathrm{F}$ (measured as the maxiumum in a draw of at least 2 gal), the occupants should be notified in the testing report.

\subsubsection{Notification Provision in All Contracts and Subcontracts}

We recommend that all contracts and subcontracts for energy retrofit work include language as discussed in Section 7.2.6. This language requires contractors and tradespeople working on a project to notify the general contractor when they discover evidence of any of a number of potential problems. The general contractor is in turn obligated to inform the owner of any such observations. This may be of particular value in remodeling projects that include demolition and offer the opportunity to inspect otherwise closed building cavities.

\subsubsection{Owner's Manual}

We recommend delivery of an owner's manual at the completion of every project. As minimum content, the manual should include manufacturer's operating instructions for any $\mathrm{CO}$ alarms installed under the project, general information on CO hazards in homes, and the EPA's $A$ Citizen's Guide to Radon (EPA 2009). 
Table 11. Summary of Minimum IEQ and Durability Testing Recommendations for Use in Building America

\begin{tabular}{|c|c|c|}
\hline Category & \begin{tabular}{|c|} 
Test or Procedure \\
\end{tabular} & Performed When \\
\hline Gas Leaks & $\begin{array}{l}\text { Maintain awareness of odors. Use a } \\
\text { "sniffer" or soap bubble solution to } \\
\text { identify gas leaks. }\end{array}$ & $\begin{array}{c}\text { When natural gas or propane is } \\
\text { used in the home }\end{array}$ \\
\hline $\begin{array}{l}\text { Combustion Safety- } \\
\text { Vented Appliances }\end{array}$ & BPI standard, with modifications & $\begin{array}{l}\text { When natural gas-, oil-, or } \\
\text { propane-fired vented } \\
\text { appliances are present }\end{array}$ \\
\hline $\begin{array}{l}\text { Combustion Safety- } \\
\text { Kitchen Ranges and } \\
\text { Other Unvented } \\
\text { Appliances }\end{array}$ & $\begin{array}{l}\text { Measure CO production of all } \\
\text { kitchen ovens, cooktop burners, and } \\
\text { unvented space heaters, fireplaces, } \\
\text { and other appliances }\end{array}$ & $\begin{array}{l}\text { When any unvented } \\
\text { combustion appliance is } \\
\text { present }\end{array}$ \\
\hline Solid Fuel Venting & Vent and chimney inspection & $\begin{array}{l}\text { When solid fuel or other } \\
\text { appliances not covered by BPI } \\
\text { test procedures are present }\end{array}$ \\
\hline CO Alarms & $\begin{array}{l}\text { Install CO alarm in mechanical area } \\
\text { and on each living level of home }\end{array}$ & $\begin{array}{c}\text { Always unless CO alarms are } \\
\text { already present }\end{array}$ \\
\hline $\begin{array}{l}\text { Mold and Moisture } \\
\text { Assessment }\end{array}$ & $\begin{array}{l}\text { Walk-through inspection and } \\
\text { occupant interview }\end{array}$ & Always \\
\hline $\begin{array}{l}\text { Radon Test Before } \\
\text { Retrofitting }\end{array}$ & 4- to 7-day charcoal canister test & $\begin{array}{l}\text { Option offered to occupants } \\
\text { (except mobile homes) }\end{array}$ \\
\hline $\begin{array}{l}\text { Radon Test After } \\
\text { Retrofitting }\end{array}$ & $\begin{array}{l}\text { 4- to 7-day charcoal canister test and } \\
\text { long-term follow-up test if required. }\end{array}$ & Always \\
\hline Lead Paint & $\begin{array}{c}\text { Comply with the EPA Lead-based } \\
\text { Paint Renovation, Repair and } \\
\text { Painting Rule. }\end{array}$ & Whenever lead paint is present \\
\hline Asbestos & $\begin{array}{c}\text { Have a professional confirm the } \\
\text { presence of ACMs before retrofit } \\
\text { work begins. }\end{array}$ & $\begin{array}{c}\text { If ACMs are suspected, in poor } \\
\text { condition and likely to be } \\
\text { disturbed in the course of the } \\
\text { work }\end{array}$ \\
\hline $\begin{array}{l}\text { Hot Water } \\
\text { Temperature }\end{array}$ & $\begin{array}{l}\text { Measure hot water temperature at the } \\
\text { kitchen or bathroom faucet closest to } \\
\text { the water heater }\end{array}$ & Always \\
\hline $\begin{array}{l}\text { Contract Notification } \\
\text { Provision }\end{array}$ & $\begin{array}{l}\text { Include language in all contracts } \\
\text { requiring contractors and } \\
\text { tradespeople working on a project to } \\
\text { notify the general contractor when } \\
\text { they discover evidence of any of a } \\
\text { number of potential problems during } \\
\text { their work }\end{array}$ & Always \\
\hline Owner's Manual & $\begin{array}{c}\text { Deliver an owner's manual at the } \\
\text { completion of a project }\end{array}$ & Always \\
\hline
\end{tabular}




\section{Further Research Needs}

In preparing this report, we have identified many areas in which further research appears to be needed. In fact, it might be more accurate to say that we cannot name any areas of IEQ and durability in which further research would be of no value.

The following suggested topics for further work are not prioritized, and represent the opinions of the authors.

\subsection{Health Effects}

Epidemiological research across a wide range of indoor air contaminants, including

- $\mathrm{CO}$ (under chronic low-level exposure)

- Radon

- Formaldehyde

- Other VOCs,

- Semivolatile organic compounds

- Halogenated fire retardants.

\subsection{Building Measurements and Modeling}

- Monitor combustion appliance spillage in large samples of homes. Observe vent system design and construction and $\mathrm{CO}$ production.

- Develop improved models of combustion appliance vent performance.

- Perform detailed analysis of the factors associated with $\mathrm{CO}$ production in combustion appliances.

- Further develop test methods for CO from unvented appliances, including range top burners and ovens that correlate with the contribution of these appliances to room air concentrations. Further measure and develop models to predict room air concentrations of $\mathrm{CO}$ based on appliance characteristics, appliance use, and ventilation.

- Continuously monitor radon concentrations, further explore the variability of radon concentrations over time, and further explore explanatory models of variability in radon concentration over time.

- Explore equilibrium constant (F factor) for radon. What are the range and variability of the equilibrium constants in U.S. homes?

- Investigate the exposure of occupants to contaminants, including radon and CO. These contaminants are likely to occur in greatly varied concentrations over time and in different parts of homes. Innovative methods may allow gathering of detailed exposure data, ultimately allowing much better epidemiologic analysis.

- Develop robust, stable, long-life, reduced cross-sensitivity CO sensors for use in CO alarms. 


\section{Conclusions}

Homes have many hazards, some of which may be caused or exacerbated by energy retrofitting or other remodeling. A number of test methods intended to identify hazards at the time of retrofitting are available and are recommended or required by various energy programs. BPI and RESNET are the leading organizations engaged in developing and codifying these methods.

Existing methods, and those addressing combustion safety and radon, are far from perfect. Typical combustion safety test methods have many flaws, and often appear to improperly classify appliances as likely to spill combustion productse under regular operating conditions. Radon testing procedures also have several flaws, and short-term testing in particular may not accurately characterize the radon level in a home.

Improvements to these and other test methods are possible. Some might be quickly implemented, some require further research and development effort.

Reliance on auditor or contractor testing may unnecessarily limit the identification and control of retrofit related hazards in a home. We suggest a broad approach to understanding, identifying, and communicating information about such hazards when retrofit projects are performed.

Before comprehensive approaches are developed and validated, energy retrofit projects should include a minimum set of IEQ and durability test requirements such as those recommended in Section 7.3. 


\section{References}

AIHA (2001). Report of Microbial Growth Task Force. Fairfax, VA: American Industrial Hygiene Association.

ALA (2007). Trends in Asthma Morbidity and Mortality. Washington, DC: American Lung Association. www.lungusa.org/finding-cures/our-research/trend-reports/asthma-trend-report.pdf (accessed January 26, 2012).

ANSI (2010). Household Cooking Gas Appliances. American National Standards Institute.

ASTM (2006). ASTM D7297-06 Standard Practice for Evaluating Residential Indoor Air Quality Concerns. West Conshohocken, PA: ASTM International.

ASTM (1998). ASTM E1998 - 11 Standard Guide for Assessing Depressurization-Induced Backdrafting and Spillage from Vented Combustion Appliances. West Conshohocken, PA: ASTM International.

Bodzin (1998). Regulating Ventless Heaters. Home Energy Magazine, Jan/Feb, 1998.

Bohac (2002) Ventilation and Depressurization Information for Houses Undergoing Remodeling. St. Paul, MN: Minnesota Department of Commerce, State Energy Office.

BPI (2005). Building Performance Institute Technical Standards for the Building Analyst Professional. Malta, NY: Building Performance Institute. http://bpi.org/Web\%20Download/BPI\%20Standards/Building Analyst Professional 1 4 12.pdf

BPI (2010). Home Energy Auditing Standard. BPI-101. Malta, NY: Building Performance Institute. http://bpi.org/Web\%20Download/BPI\%20Standards/BPI-

101 Home Energy Auditing_Standard_Aug_3 2010.pdf

BPI (2011). Informative Clarification: Definition and Reclassification of an Orphaned Natural Draft Water Heater Converted to a Stand-Alone Natural Draft Water Heater. Malta, NY:

Building Performance

Institute. www.bpi.org/files/pdf/BA_Clarification_of CAZ_Depressurization_Limits_v2.pdf

BPI (2012). Combustion Safety Test Procedure for Vented Appliances. Malta, NY: Building Performance Institute. http://bpi.org/files/pdf/CombustionSafetyTestProcedure-GoldSheet.pdf

Brennan (2011). Personal communication, Terry Brennan, 21 Feb 2011

CDC (2008). Morbidity and Mortality Weekly Report: Nonfatal, Unintentional, Non-FireRelated Carbon Monoxide Exposures - United States, 2004 - 2006. Atlanta, GA: Centers for Disease Control and Prevention. www.cdc.gov/mmwr/preview $/ \mathrm{mmwrhtml} / \mathrm{mm} 5733 \mathrm{a} 2 . \mathrm{htm}$ (accessed January 26, 2012). 
CDC (2007). Morbidity and Mortality Weekly Report: Carbon Monoxide-Related Deaths United States, 1999 - 2004. Atlanta, GA: Centers for Disease Control and

Prevention. www.cdc.gov/mmwr/preview/mmwrhtml/mm5650a1.htm (accessed January 26, 2012).

CDC (2011). NIOSH Pocket Guide to Chemical Hazards. Atlanta, GA: Centers for Disease Control and Prevention. www.cdc.gov/niosh/npg/pgintrod.html

CDC (2011). Indoor Environmental Quality: Dampness and Mold in Buildings. Atlanta, GA: Centers for Disease Control and Prevention. www.cdc.gov/niosh/topics/indoorenv/mold.html (accessed 1/24/2012).

CDC (2004). Carbon Monoxide Poisoning from Hurricane-Associated Use of Portable Generators-Florida. Atlanta, GA: Centers for Disease Control and

Prevention. www.cdc.gov/mmwr/preview/mmwrhtml $/ \mathrm{mm} 5428 \mathrm{a} 2 . \mathrm{htm}$

CDC (2005). Unintentional Non-Fire-Related Carbon Monoxide Exposures-United States, 2001-2003. Atlanta, GA: Centers for Disease Control and

Prevention. www.cdc.gov/mmwr/preview $/ \mathrm{mmwrhtml} / \mathrm{mm} 5402 \mathrm{a} 2 . \mathrm{htm}$

CDC (1996). Deaths from Motor-Vehicle Related Unintentional Carbon Monoxide Poisoning Colorado, 1996, New Mexico, 1980-1995, and United States, 1979-1992. Atlanta, GA: Centers for Disease Control and Prevention. www.cdc.gov/mmwr/preview/mmwrhtml/00044617.htm

CMCH (2004). Residential Combustion Spillage Monitoring, Technical Series 04-101. Ottawa, ON: Canada Mortgage and Housing Corporation.

CMHC (2005). Development and Evaluation of a new Depressurization Spillage Test for Residential Gas-Fired Combustion Appliances. Ottawa, ON: Canada Mortgage and Housing Corporation.

CPSC (1977). CPSC Announces Final Ban on Lead-Containing Paint. Bethesda, MD: Consumer Product Safety Commission. www.cpsc.gov/cpscpub/prerel/prhtml77/77096.html (accessed December 4, 2012).

CPSC (2011). Miller, D. and Chowdhury, R. U.S. National Estimates of Fires, Deaths, Injuries, and Property Losses from Unintentional Fires. Bethesda, MD: Consumer Product Safety Commission. www.cpsc.gov/library/fire08.pdf (accessed January 26, 2012).

DOL (1986). Safety and Health Regulations for Construction (29 CFR Part 1926, subpart Z). Wahsington, DC: U.S. Department of Labor.

EERE-BA (2011). Building America - Resources for Energy Efficient Homes: Program Goals. www1.eere.energy.gov/buildings/building_america/program_goals.html (accessed February 3, 2012). 
EMSL (2010). Microbiology Sampling Guide. Cinnaminson, NJ:EMSL Analytical, Inc. www.emsl.com/PDFDocuments/SamplingGuide/EMSLMicrobiologySamplingGuide.pdf

EPA (1986). Seasonal Variations of Radon and Radon Decay Product Concentrations in Single Family Homes. Washington, DC: U.S. Environmental Protection Agency.

EPA (2009). A citizen's guide to radon. Washington, DC: U.S. Environmental Protection Agency. www.epa.gov/radon/pubs/citguide.html

EPA (2010a). Asbestos Ban and Phase Out. Washington, DC: U.S. Environmental Protection Agency. www.epa.gov/asbestos/pubs/ban.html

EPA (2010b). Asbestos in Your Home. Washington, DC: U.S. Environmental Protection Agency. www.epa.gov/asbestos/pubs/ashome.html

EPA (2011). Basic Information about Radon in Drinking Water. Washington, DC: U.S. Environmental Protection Agency. http://water.epa.gov/lawsregs/rulesregs/sdwa/radon/ basicinformation.cfm (Accessed January 17, 2012).

EPA (2011a). Healthy Indoor Environment Protocols for Home Energy Upgrades. Washington, DC: U.S. Environmental Protection Agency. www.epa.gov/iaq/pdfs/epa_retrofit_protocols.pdf

EPA (2011b). Lead in Paint, Dust, and Soil: Basic Information. Washington, DC: U.S. Environmental Protection Agency. www.epa.gov/lead/pubs/leadinfo.htm\#health

EPA (2011c). An Introduction to Indoor Air Quality (IAQ): Formaldehyde. Washington, DC: U.S. Environmental Protection Agency. www.epa.gov/iaq/formalde.html (accessed January 30, 2012).

EPA (2011d). Asthma Facts. Washington, DC: U.S. Environmental Protection Agency. www.epa.gov/asthma/pdfs/asthma fact sheet_en.pdf

EPA (2011e). EPA Recognition of Lead Test Kits. Washington, DC: U.S. Environmental Protection Agency. www.epa.gov/lead/pubs/testkit.htm

EPA (2011f). Particulate Matter. Washington, DC: U.S. Environmental Protection Agency. www.epa.gov/pm/health.html

EPA (2012). The Key to Mold Control is Moisture Control. Washington, DC: U.S. Environmental Protection Agency. www.nyc.gov/html/doh/html/epi/moldrpt1.shtml

EPA Website: A Brief Guide to Mold, Moisture, and Your Home. www.epa.gov/mold/moldbasics.html 
FPL (2010). Wood Handbook, Wood as an Engineering Material, chapter 14. Madison, WI: U.S. Department of Agriculture, Forest Service, Forest Products

Laboratory. www.fpl.fs.fed.us/documnts/fplgtr/fplgtr190/chapter_14.pdf

GRI (1995). Depressurization, Backdrafting, and Spillage from Vented Gas Appliances_A Literature Review. Chicago, IL: Gas Research Institute.

Hampson (2011). Residential carbon monoxide poisoning from motor vehicles. American Journal of Emergency Medicine, 29(1): 75-7. www.ncbi.nlm.nih.gov/pubmed/20825787

HUD (2000). Residential Rehabilitation Inspection Guide. Washington, DC: U.S. Department of Housing and Urban Development. www.huduser.org/portal/publications/rehabinspect.pdf

Karg (2001). Field Protocol for Gas Range Carbon Monoxide Emissions Testing (for the Chicago Regional Diagnostics Working Group). Bethel, ME: R.J. Karg Associates.

Karg (2009). CO Hot Pot: A Tool for the Standardized Testing of Carbon Monoxide and other Emissions from Gas Range Burners. Bethel, ME: R.J. Karg Associates http://karg.com/cohotpot.htm (accessed 1/29/2012).

Koontz (2002). Depressurization-Induced Backdrafting and Spillage: Implications of Results from North American Field Studies. Atlanta, GA: American Society of Heating, Refrigerating and Air Conditioning Engineers.

Lewis (2009). A Living Radon Reference Manual. Pennsylvania Department of Environmental Protection, Bureau of Radiation Protection, Radon

Division www.aarst.org/proceedings/2009/A LIVING RADON REFERENCE MANUAL.pdf

May, J. (2001). My House is Killing Me! The Johns Hopkins University Press, Baltimore, MD.

MHRA (2000). Moisture Problems in Manufactured Housing. New York, NY:Manufactured Housing Research Alliance. www.huduser.org/portal/publications/moisture.pdf

NCI (2009). Asbestos Exposure and Cancer Risk. Bethesda, MD: National Cancer Institute. http://www.cancer.gov/cancertopics/factsheet/Risk/asbestos (accessed December 4, 2012).

NCI (2011). Radon and Cancer. Bethesda, MD: National Cancer Institute at the National Institutes of Health. www.cancer.gov/cancertopics/factsheet/Risk/radon

NFPA (2011). Home Structure Fires. Quincy, MA: National Fire Protection Association. www.nfpa.org/assets/files/pdf/os.homes.pdf

NFPA (2012). National Fuel Gas Code. Quincy, MA: National Fire Protection Association. 
NYCDHMH (2008). Guidelines on Assessment and Remediation of Fungi in Indoor Environments. New York, NY: New York City Department of Health and Mental Hygiene. www.nyc.gov/html/doh/html/epi/moldrpt1.shtml

OEHHA (2008). Formaldehyde Reference Exposure Levels Draft. Sacramento, CA: State of California Office of Environmental Health Hazard Assessment. http://oehha.ca.gov/air/toxic contaminants/pdf zip/formaldehyde 112508.pdf

OSHA (2012). Occupational Safety and Health Guideline for Carbon Monoxide. Washington, DC: U.S. Department of Labor, Occupational Safety \& Health Administration. www.osha.gov/SLTC/healthguidelines/carbonmonoxide/recognition.html (Accessed 17 Jan 2012).

Pigg (2010). Energy use by Residential Gas Water Heaters: A technical field study in 10 Wisconsin homes. Madison, WI: Energy Center of Wisconsin.

RESNET (2010). RESNET Interim Guidelines for Combustion Appliance Testing and Writing Work Scope. Residential Energy Services Network. www.resnet.us/standards/ RESNET_interim_guidelines_for_combustion_safety_scope_of_work.pdf

Ramola (2003). Measurement of Equilibrium Factor "F" between Radon and its Progeny and Thoron and its Progeny in the Indoor Atmosphere Using Nuclear Track Detectors. Indoor and Built Environment October 2003 vol. 12 no. 5 351-355.

Steck (2004). Indoor radon exposure uncertainties cause by temporal variation. Madrid, Spain: $11^{\text {th }}$ International Congress of the International Radiation Protection Association. http://irpa11.irpa.net/pdfs/6a60.pdf

Steck (1999). Intercomparison of Retrospective Radon Detectors. Envirnomental Health Perspectives 107:11, November 1999.

Steck (2009). Annual average indoor radon variations over two decades. Health Physics, Jan: 96(1):37-47.

Steck (2011). Personal communication, Daniel Steck, March 3, 2011.

Sterner (2010). Combustion Appliance Testing Can Be Easy if You Understand What and Why You Are Testing. Berkeley, CA: Lawrence Berkeley National Laboratory, Home Energy Pros. http://homeenergypros.lbl.gov/forum/topics/combustion-appliance-testing (accessed February 2, 2012).

USA Today (2011). Feds: Response To Snowstorm Slower Than To Irene. www.usatoday.com/weather/storms/winter/story/2011-11-01/snowstorm-northeastresponse $/ 51034350 / 1$ ?csp=34news\&utm source=feedburner\&utm medium=feed\&utm campaig

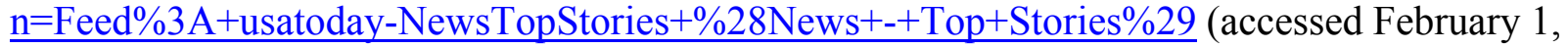
2012) 
WDNR (2003). When should I test my well water? Madison, WI: Wisconsin Department of Natural Resources. http://dnr.wi.gov/org/water/dwg/welltest.htm (Accessed January 17, 2012).

Yost (2012). Personal communication, January 3, 2012, Nathan Yost, M.D.

Zhang (2007). Variation in Yearly Residential Radon Concentrations in the Upper Midwest. Health Physics, Oct: 93(4):288-297. 


\title{
Table 1 Sources
}

\author{
Allergens \\ Washington DC: U.S. Department of Housing and Urban \\ Development. http://portal.hud.gov/hudportal/documents/huddoc?id=DOC 13701.pdf (accessed \\ January 26, 2012).

\section{Asbestos} \\ Mesothelioma Center (2011). Asbestos Cancer Facts and \\ Statistics. www.asbestos.com/cancer/facts.php (accessed January 26, 2012).
}

HUD (2009). Leading our Nation to Healthier Homes: The Healthy Homes Strategic Plan, p. 41.

AAFP (2007). O’Reilly, K. et al. Asbestos-related Lung Disease. Leawood, KS: American Academy of Family Physicians. www.aafp.org/afp/2007/0301/p683.html (accessed January 26, 2012).

ALA (2007). Trends in Asthma Morbidity and Mortality. Washington, DC: American Lung Association. www.lungusa.org/finding-cures/our-research/trend-reports/asthma-trend-report.pdf (accessed January 26, 2012).

\section{Asthma}

EPA c (2011). Asthma Facts. Washington, DC: U.S. Environmental Protection Agency. www.epa.gov/asthma/pdfs/asthma fact_sheet en.pdf

\section{Carbon Monoxide}

CDC (2008). Morbidity and Mortality Weekly Report: Nonfatal, Unintentional, Non-FireRelated Carbon Monoxide Exposures - United States, 2004 - 2006. Atlanta, GA: Centers for Disease Control and Prevention. www.cdc.gov/mmwr/preview $/ \mathrm{mmwrhtml} / \mathrm{mm} 5733 \mathrm{a} 2 . \mathrm{htm}$ (accessed January 26, 2012).

CDC (2007). Morbidity and Mortality Weekly Report: Carbon Monoxide-Related Deaths United States, 1999 - 2004. Atlanta, GA: Centers for Disease Control and Prevention. www.cdc.gov/mmwr/preview $/ \mathrm{mmwrhtml} / \mathrm{mm} 5650 \mathrm{a} 1 . \mathrm{htm}$ (accessed January 26, 2012).

CDC (2011). National Environmental Public Health Tracking Network: Carbon Monoxide Poisoning. Atlanta, GA: Centers for Disease Control and Prevention. http://ephtracking.cdc.gov/showCarbonMonoxideLanding.action

CDC (2005). Unintentional Non-Fire-Related Carbon Monoxide Exposures-United States, 2001-2003. Atlanta, GA: Centers for Disease Control and

Prevention. www.cdc.gov $/ \mathrm{mmwr} / \mathrm{preview} / \mathrm{mmwrhtml} / \mathrm{mm} 5402 \mathrm{a} 2 . \mathrm{htm}$

CPSC (2011). Non-Fire Carbon Monoxide Deaths Associated with the Use of Consumer Products: 2007 Annual Estimates. Bethesda, MD: U.S. Consumer Product Safety Commission. 


\section{Fires}

CPSC (2011). Miller, D. and Chowdhury, R. U.S. National Estimates of Fires, Deaths, Injuries, and Property Losses from Unintentional Fires. Bethesda, MD: Consumer Product Safety

Commission. www.cpsc.gov/library/fire08.pdf (accessed January 26, 2012).

NFPA (2011). Home Structure Fires. Quincy, MA: National Fire Protection

Association. www.nfpa.org/assets/files/pdf/os.homes.pdf

\section{Fungal Decay}

NPMA. Termite FAQ. Fairfax, VA: National Pest Management

Association. www.pestworld.org/termite-inspection (accessed January 26, 2012).

\section{Lead}

CDC (2008). Number of Children Tested and Confirmed EBLLs by State, Year, and BLL Group, Children $<72$ Months. Atlanta, GA: Centers for Disease Control and

Prevention. www.cdc.gov/nceh/lead/data/StateConfirmedByYear_1997_2008Excel.htm (accessed January 26, 2012).

\section{Radon}

NCI (2011). Radon and Cancer. Bethesda, MD: National Cancer Institute at the National Institutes of Health. www.cancer.gov/cancertopics/factsheet/Risk/radon

EPA (2012). Radon Health Risks. Washington, DC: U.S. Environmental Protection Agency. www.epa.gov/radon/healthrisks.html (accessed January 26, 2012).

\section{Secondhand smoke}

HUD (2009). Leading our Nation to Healthier Homes: The Healthy Homes Strategic Plan, p.49. Washington, DC: U.S. Department of Housing and Urban Development. http://portal.hud.gov/hudportal/documents/huddoc?id=DOC 13701.pdf (accessed January 26, 2012).

CDC (2012). Smoking and Tobacco Use: Tobacco-Related Mortality. Atlanta, GA: Centers for Disease Control and

Prevention. www.cdc.gov/tobacco/data_statistics/fact_sheets/health_effects/tobacco_related_mor tality/\#shs (accessed January 26, 2012).

\section{Accidental Injuries}

CDC. National Center for Injury Prevention and

Control, http://webappa.cdc.gov/sasweb/ncipc/nfirates2001.html and WISQARS Injury

Mortality Reports, 1999 - 2007, http://webappa.cdc.gov/sasweb/ncipc/mortrate10 sy.html (accessed January 26, 2012).

\section{Auto accidents}

CDC (2011). Morbidity and Mortality Weekly Report_-Vital Signs: Nonfatal, Motor Vehicle Occupant Injuries (2009) and Seat Belt Use (2008) Among Adults - United States. Atlanta, GA: 
Centers for Disease Control and

Prevention. www.cdc.gov/mmwr/preview/mmwrhtml $/ \mathrm{mm} 5951 \mathrm{a3} . \mathrm{htm}$ (accessed January 26, 2012).

NHTSA (2012). Fatality Analysis Reporting System. Washington, DC: National Highway Traffic Safety Administration. www-fars.nhtsa.dot.gov/Main/index.aspx (accessed January 26, 2012).

\section{Legionnaires disease}

CDC (2011). Legionellosis Resource Site. Patient Facts: Learn More about Legionnaires' disease. Atlanta, GA: Centers for Disease Control and

Prevention. www.cdc.gov/legionella/patient_facts.htm (accessed January 26, 2012).

\section{Lightning}

NOAA (2010). Medical Aspects of Lightning. Washington, DC: National Oceanic and Atmospheric Administration, National Weather

Service. www.lightningsafety.noaa.gov/medical.htm (accessed 1/28/2012).

\section{Pesticide exposure}

HUD (2009). Leading our Nation to Healthier Homes: The Healthy Homes Strategic Plan, p.48. Washington, DC: U.S. Department of Housing and Urban

Development. http://portal.hud.gov/hudportal/documents/huddoc?id=DOC 13701.pdf (accessed January 26, 2012).

\section{Suicide}

AFSP (2012). New York, NY: American Foundation for Suicide Prevention. Facts and

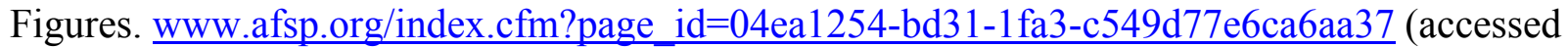
January 26, 2012).

\section{Unintentional poisoning}

CDC (2012). National Center for Injury Prevention and Control, WISQARS Nonfatal Injury Reports. Atlanta, GA: Centers for Disease Control and Prevention. http://webappa.cdc.gov/sasweb/ncipc/nfirates2001.html (accessed January 26, 2012).

CDC (2012). FastStats. Accidents or Unintentional Injuries. Atlanta, GA: Centers for Disease Control and Prevention. www.cdc.gov/nchs/fastats/acc-inj.htm (accessed January 26, 2012). 


\section{Appendix A Draft Forces}

The flow through the venting systems of natural-draft water heaters (and other natural-draft combustion appliances) is a function of several factors, including the relative temperatures (and densities) of combustion products in the vent system and of outdoor air, the vertical height of the venting system, frictional characteristics of the system, and the relative pressure of the room or CAZ compared to the outdoors.

In all cases, the functioning of a natural-draft chimney depends on the differential density of air in the chimney compared to its environment. The environment in this case is outdoor air, because chimneys exhaust to outdoor air, and the temperature and density of outdoor air are the primary factors yielding a pressure difference at the base of a chimney. This density-driven pressure is the maximum pressure available to drive chimney flow, before frictional losses or pressure difference across the building envelope are accounted for. ASHRAE uses the term theoretical draft for this basic driving force in natural-draft chimney flow, and suggests it be calculated as follows: ${ }^{11}$

$$
\text { Theoretical draft }(\mathrm{Pa})=1902.1(\mathrm{H})\left(1 / \mathrm{T}_{\text {out }}-1 / \mathrm{T}_{\text {vent }}\right)
$$

where

$\mathrm{H}=$ the vertical height of the vent system (ft)

$\mathrm{T}_{\text {out }}=$ outdoor temperature $(\mathrm{R})$

$\mathrm{T}_{\text {vent }}=\quad$ the mean vent temperature $(\mathrm{R})$.

The full theoretical draft pressure is not necessarily available to drive vent flow, because any pressure drop across the building envelope (from outside to inside) reduces the net pressure difference.

Theoretical draft provides an upper limit on allowable depressurization; if zone depressurization exceeds theoretical draft, reverse flow in the chimney is inevitable. Figure 2 shows theoretical draft pressures for chimney heights typical of those observed in other research (Pigg 2010), at the lower range of temperatures characteristic ofoperation of a pilot light flame. In general, the vent temperatures observed in this study were at least $30^{\circ} \mathrm{F}$ above outdoor ambient temperature, except one natural-draft water, where lower vent temperatures were in part a consequence of a very tall chimney.

\footnotetext{
${ }^{11}$ HVAC Systems and Equipment Handbook, ASHRAE 2004, chapter 30. We have modified the equation as presented to use a standard pressure of 14.696 psia and to present the result in Pa.
} 


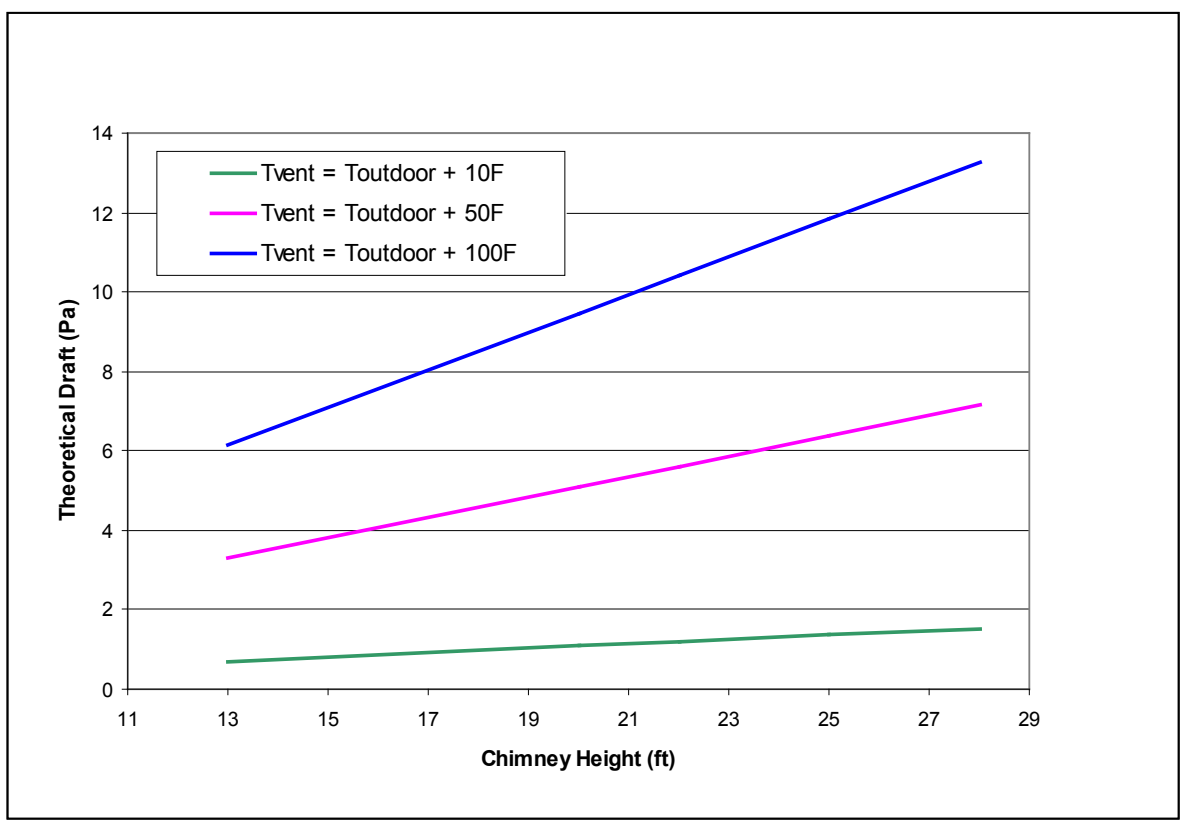

Figure 2. Theoretical chimney draft for varying vent temperature rise (low range) at $T_{\text {out }}=60^{\circ} \mathrm{F}$

These modest driving forces help explain downdrafting (flow reversal) in the vent system during pilot-only operation. Flow reversal is more likely to occur when outdoor temperatures are moderately cool rather than very cold or hot, for two reasons:

- Theoretical draft provides a lower driving force at moderate outdoor temperatures than at very cold temperatures, and thus is more easily overcome by wind or depressurization.

- The depressurization of the basement (or location of chimney inlet) caused by stack effect pressures when it is colder outside than inside encourages downdrafting.

Because chimneys venting water heaters are normally heated to some degree by continuous vent losses and maintain a continuous upward stack effect flow, the downdrafting must be initially established by a force sufficient to, at least briefly, overcome the stack effect. These forces may include exhaust depressurization to a point that overcomes normal stack effect forces, or wind gusts, or a combination of these. Once the chimney is filled with the cooler air, the downflow may be self-sustaining with only moderate CAZ depressurization.

Measured draft pressure (the pressure difference between a point just beyond the draft hood in the vent system with respect to the room or zone containing the vent system inlet) can on one hand be thought of as a measure of flow into the vent system: higher driving forces yield higher flows, and these higher flows are evidenced by higher pressure drop from room to vent. We used draft pressure, calibrated against flow rates derived from gas measurements for each system, as a general means of measuring vent flows. Draft pressure is also one measure of the forces driving vent flow, though it is always less than the total driving force acting over the length of the chimney. 


\section{Appendix B Radon Measurement Method Definitions}

Excerpted from U.S. EPA National Radon Proficiency Program Handbook, Appendix A: Radon Proficiency Program (www.epa.gov/radon/pdfs/measurement_methods.pdf).

Measurement Method Definitions, pp 70-74, July 1996. Listed below are brief descriptions of each of the 12 radon measurement methods and 3 radon decay product measurement methods that have been identified by the U.S. EPA and were used in EPA's former National Radon Proficiency Program. Information on how to find a qualified radon service provider in your area is presented below.

\section{RADON GAS MEASUREMENT METHODS}

\section{AC - Activated Charcoal Adsorption}

For this method, an airtight container with activated charcoal is opened in the area to be sampled and radon in the air adsorbs onto the charcoal granules. At the end of the sampling period, the container is sealed and may be sent to a laboratory for analysis.

The gamma decay from the radon adsorbed to the charcoal is counted on a scintillation detector and a calculation based on calibration information is used to calculate the radon concentration at the sample site.

Charcoal adsorption detectors, depending on design, are deployed from 2 to 7 days. Because charcoal allows continual adsorption and desorption of radon, the method does not give a true integrated measurement over the exposure time. Use of a diffusion barrier over the charcoal reduces the effects of drafts and high humidity.

\section{AT - Alpha Track Detection (filtered)}

For this method, the detector is a small piece of special plastic or film inside a small container. Air being tested diffuses through a filter covering a hole in the container. When alpha particles from radon and its decay products strike the detector, they cause damage tracks. At the end of the test the container is sealed and returned to a laboratory for reading.

The plastic or film detector is treated to enhance the damage tracks and then the tracks over a predetermined area are counted using a microscope or optical reader. The number of tracks per area counted is used to calculate the radon concentration of the site tested. Exposure of alpha track detectors is usually 3 to 12 months, but because they are true integrating devices, alpha track detectors may be exposed for shorter lengths of time when they are measuring higher radon concentrations.

\section{UT - Unfiltered Track Detection}

The unfiltered alpha track detector operates on the same principle as the alpha track detector, except that there is no filter present to remove radon decay products and other alpha particle emitters. Without a filter, the concentration of radon decay products decaying within the "striking range" of the detector depends on the equilibrium ratio of radon decay products to radon present in the area being tested, not simply the concentration of radon. Unfiltered detectors 
that use cellulose nitrate film exhibit an energy dependency that causes radon decay products that plate out on the detector not to be recorded.

This phenomenon lessens, but does not totally compensate for the dependency of the calibration factor on equilibrium ratio. For this reason, EPA currently recommends that these devices not be used when the equilibrium fraction is less than 0.35 or greater than 0.60 without adjusting the calibration factor.

\section{LS - Charcoal Liquid Scintillation}

This method employs a small vial containing activated charcoal for sampling the radon. After an exposure period of 2 to 7 days (depending on design) the vial is sealed and returned to a laboratory for analysis. While the adsorption of radon onto the charcoal is the same as for the AC method, analysis is accomplished by treating the charcoal with a scintillation fluid, then analyzing the fluid using a scintillation counter. The radon concentration of the sample site is determined by converting from counts per minute.

\section{CR - Continuous Radon Monitoring}

This method category includes those devices that record real-time continuous measurements of radon gas. Air is either pumped or diffuses into a counting chamber. The counting chamber is typically a scintillation cell or ionization chamber. Scintillation counts are processed by electronics, and radon concentrations for predetermined intervals are stored in the instrument's memory or transmitted directly to a printer.

\section{EL - Electret lon Chamber: Long-Term}

For this method, an electrostatically charged disk detector (electret) is situated within a small container (ion chamber). During the measurement period, radon diffuses through a filter-covered opening in the chamber, where the ionization resulting from the decay of radon and its progeny reduces the voltage on the electret. A calibration factor relates the measured drop in voltage to the radon concentration. Variations in electret design determine whether detectors are appropriate for making long-term or short-term measurements. EL detectors may be deployed for 1 to 12 months. Since the electret-ion chambers are true integrating detectors, the EL type can be exposed at shorter intervals if radon levels are sufficiently high.

\section{ES - Electret lon Chamber: Short-Term}

For this method, an electro statically charged disk detector (electret) is situated within a small container (ion chamber). During the measurement period, radon diffuses through a filter-covered opening in the chamber, where the ionization resulting from the decay of radon and its progeny reduces the voltage on the electret. A calibration factor relates the measured drop in voltage to the radon concentration. Variations in electret design determine whether detectors are appropriate for making long-term or short-term measurements. ES detectors may be deployed for 2 to 7 days. Since electret-ion chambers are true integrating detectors, the ES type can be exposed at longer intervals if radon levels are sufficiently low.

\section{GC - Grab Radon/Activated Charcoal}

This method requires a skilled technician to sample radon by using a pump or a fan to draw air through a cartridge filled with activated charcoal. Depending on the cartridge design and airflow, sampling takes from 15 minutes to 1 hour. After sampling, the cartridge is placed in a sealed 
container and taken to a laboratory where analysis is approximately the same as for the AC or LS methods.

\section{GB - Grab Radon/Pump-Collapsible Bag}

This method uses a sample bag made of material impervious to radon. At the sample site, a skilled technician using a portable pump fills the bag with air, then transports it to the laboratory for analysis. Usually, the analysis method is to transfer air from the bag to a scintillation cell and perform analysis in the manner described for the grab radon/scintillation cell (GS) method below.

\section{GS - Grab Radon/Scintillation Cell}

For this method, a skilled operator draws air through a filter to remove radon decay products into a scintillation cell either by opening a valve on a scintillation cell that has previously been evacuated using a vacuum pump or by drawing air through the cell until air inside the cell is in equilibrium with the air being sampled, then sealed. To analyze the air sample, the window end of the cell is placed on a photomultiplier tube to count the scintillations (light pulses) produced when alpha particles from radon decay strike the zinc sulfide coating on the inside of the cell. A calculation is made to convert the counts to radon concentrations.

\section{SC - Three-Day Integrating Evacuated Scintillation Cell}

For this method, a scintillation cell is fitted with a restrictor valve and a negative pressure gauge. Prior to deployment, the scintillation cell is evacuated. At the sample site, a skilled technician notes negative pressure reading and opens the valve. The flow through the valve is slow enough that it takes more than the 3-day sample period to fill the cell. At the end of the sample period, the technician closes the valve, notes the negative pressure gauge reading, and returns with the cell to the laboratory. Analysis procedures are approximately the same as for the GS method described above. A variation of this method involves use of the above valve on a rigid container requiring that the sampled air be transferred to a scintillation cell for analysis.

\section{PB - Pump-Collapsible Bag (1-day)}

For this method, a sample bag impervious to radon is filled over a 24 -hour period. This is usually accomplished by a pump Programmed to pump small amounts of air at predetermined intervals during the sampling period. After sampling, analysis procedures are similar to those for the GB method.

\section{RADON DECAY PRODUCT MEASUREMENT METHODS}

\section{CW - Continuous Working Level Monitoring}

This method encompasses those devices that record real-time continuous measurement of radon decay products. Radon decay products are sampled by continuously pumping air through a filter. A detector such as a diffused-junction or surface-barrier detector counts the alpha particles produced by radon decay products as they decay on this filter. The monitor typically contains a microprocessor that stores the number of counts for predetermined time intervals for later recall. Measurement time for the Program measurement test is approximately 24 hours. 


\section{GW - Grab Working Level}

For this method, a known volume of air is pulled through a filter, collecting the radon decay products onto the filter. Sampling time usually is 5 minutes. The decay products are counted using an alpha detector. Counting must be done with precise timing after the filter sample is taken. The two counting procedures most commonly used are the Kusnitz and the Tsivoglou methods described in the Indoor Radon and Radon Decay Product Measurement Device Protocols.

\section{RP - Radon Progeny (Decay Product) Integrating Sampling Unit}

For this method, a low-flow air pump pulls air continuously through a filter. Depending on the detector used, the radiation emitted by the decay products trapped on the filter is registered on two thermoluminescent dosimeters (TLDs), an alpha track detector, or an electret. The devices presently available require access to a household electrical supply, but do not require a skilled operator. Deployment simply requires turning the device on at the start of the sampling period and off at the end.

The sampling period should be at least 72 hours. After sampling, the detector assembly is shipped to a laboratory where analysis of the alpha track and electret types is performed using procedures described for these devices (AT, EL, and ES) elsewhere in this appendix. The TLD detectors are analyzed by an instrument that heats the TLD detector and measures the light emitted. A calculation converts the light measurement to radon concentrations. 


\section{U.S. DEPARTMENT OF Energy Efficiency \& ENERY Renewable Energy}

